\title{
Development of transformation bands in ceria-stabilized- zirconia based composites during bending at room
}

\section{temperature}

\author{
Aléthéa Liens $^{\mathrm{a}, \mathrm{b}}$, Michael Swain ${ }^{\mathrm{c}, \mathrm{d}}$, Helen Reveron ${ }^{\mathrm{a}}$, Jérôme Cavoret ${ }^{\mathrm{e}}$, Philippe Sainsot ${ }^{\mathrm{e}}$, \\ Nicolas Courtois $^{\mathrm{b}}$, Damien Fabrègue ${ }^{\mathrm{a}}$, Jérôme Chevalier ${ }^{\mathbf{a}^{*}}$ \\ ${ }^{a}$ Université de Lyon, INSA-Lyon, UMR CNRS 5510 MATEIS, 20 Avenue Albert Einstein, 69621 \\ Villeurbanne Cedex, France \\ ${ }^{\mathrm{b}}$ Anthogyr SAS, 2237 avenue A. Lasquin 74700 Sallanches, France \\ ${ }^{\mathrm{c}}$ AMME, University of Sydney, NSW 2006 Australia \\ ${ }^{\mathrm{d}}$ Engineering, Don State Technical University, Rostov-on Don, Russia. \\ ${ }^{\mathrm{e}}$ Laboratoire de Mecanique des Contacts et des Structures (LaMCoS), INSA de Lyon, France \\ * Corresponding author: jerome.chevalier@insa-lyon.fr; Tel : +33(0)4-72-43-61-25
}

\begin{abstract}
Transformation-induced plasticity in a ceria-stabilized-zirconia based composite was studied in four-point bending, with particular emphasis on nucleation and growth of tetragonal-tomonoclinic transformation bands. They initiated on the side in tension at a given value of stress and grow in size and number with increased applied load. The spacing between them was related to samples' thickness: thicker samples led to a smaller number of larger/deeper bands. Residual stresses around indentations, placed on the tensile surface of some samples, triggered transformation bands nucleation but had no significant effect on the final total number of bands. A simple stress shielding model suggests that wide bands hinder adjacent thinner bands to propagate and expand because of stress shielding around them. Nucleation of a given transformation band is thus related to: (i) stress concentrations at the surface, (ii) geometry (stress-field inside the sample) and (iii) a shielding effect from the bands already present.
\end{abstract}

Keywords: Zirconia, plasticity, phase transformation, $\mathrm{CeO}_{2}, \mathrm{ZrO}_{2}$. 


\section{Introduction}

Transformation toughening in zirconia-containing ceramics involves an increase of crack resistance thanks to the tetragonal to monoclinic $(t-m)$ phase transformation occurring at the crack-tip. It has been described and applied mostly to yttria-doped zirconia systems [1-4]. Literature is less abundant, but quite consistent about transformation-induced plasticity especially for ceria-doped zirconia systems, for which phase transformation may occur before crack propagation, leading to genuine ductility [5-10].

Studies on Ceria-doped Tetragonal Zirconia Polycrystals (Ce-TZP) have shown that the transformation-induced plasticity is a stress-assisted phenomenon [11, 12], which occurs by a strain accommodation from $t-m$ transformation variants development [13]. It is manifested by the formation of visible transformation bands leading to inhomogeneous and localized distribution of the monoclinic phase inside the material [8]. This localization of $t-m$ transformation and thus plasticity is in some aspect analogous with Lüders bands present in some metallic materials [14], although the mechanism of plasticity is different. During fourpoint bending experiments, observations have shown that transformation bands were only present on the tensile side of samples and did not penetrate to the compressive side, highlighting the stress-state sensitivity and the asymmetric nature of the transformation [11]. The deformation bands were found to exhibit a wedge-like shape with a tip close to the neutral axis of the beam and appeared as spaced parallel bands on the tensile side of the samples [13,15-16]. They were oriented normal to the maximum principal stress [8]. A study by Rauchs et al. [16] predicted that the thickness of these bands should increase with deformation, but that was not demonstrated experimentally. Previous literature has shown that the formation of these transformation bands was visible as localized uplifts on the tensile surface of tested samples and lead to irreversible plastic strain and permanent bending of the tested beam $[4-8,11,12,17]$. However, the uplift of the bands was not precisely quantified or analyzed. The nucleation and then growth of transformation bands was manifested either as load drops during bending or as smooth hardening, evident on the stress-strain curves [11, 12]. In the latter case (i.e. homogeneous phase transformation), the transformation strain was found to increase with the applied stress (increased inelastic deformation) and led to the initial deviation on the S-S curves from typical linear-elastic behavior $[5,8]$.

The nucleation and development of transformation bands has been the subject of intensive research and mathematical modelling but is still not fully described experimentally. Previous studies by Reyes Morel and Chen [11, 12] have shown that the probability of a band's 
nucleation depends on the availability of a nucleating defect and the exhaustion process of nucleating defects in a sample gives rise to the observed strain hardening effect. However, they emphasized that the formation of such bands merits special discussion in relation to its implication on strength and fracture in Ce-TZP ceramics [11]. Stump [18] emphasized the role of pre-existing nucleation sites or defects on the formation of bands and suggested that there was a critical defect or nucleation size for their development. The condition for nucleation is dependent upon the tensile stress and volume dilatation rather than the shear stress, which is different from plasticity in metals. Experimental observations and analysis by Rauchs et al. [8] for a number of Ce-TZP materials with different grain sizes and in different tensile loading configurations, strongly supported the mean principal stress criteria for transformation but noted the presence of both stress-induced transformation plasticity and autocatalytic transformation plasticity with the former behavior generally preceding the latter except for large grain sized specimens. These authors also noted that the presence of defects could be responsible for the onset of transformation but the extent of the associated plasticity was considered as small compared with the autocatalytic behavior (spontaneous formation and development of transformation bands, without the necessary presence of defects or initial stress concentrations). To illustrate the impact of pre-existing residual stresses, Reyes Morel and Chen found [11], when Vickers indents were introduced onto a 12 mol.\% Ce-TZP specimen, which was then loaded in flexure to fracture, that there were almost no indents with visible cracks, even though deformation bands emanated from the corners in tension of all indents. The latter were argued to be directly related to the residual stresses associated with the indentations [11]. The experiments were performed on indented samples with large imprints (roughly 200 microns diagonal size from the images provided) and no annealing was performed after indentation. As the goal was mainly to illustrate, rather than quantify, the effect of indentation residual stress field, the impact of indentations on the transformation bands nucleation/growth was not fully examined.

Plastic deformation being highly heterogeneous and localized to wedge-like bands during 4point bending (4PB) tests suggests a large stress-redistribution is expected. Raman spectroscopy studies from Sergo et al. [13, 17] have shown that the bands, after unloading, were under compression, highlighting high residual stresses due to the transformation. The magnitude of the compression stresses was found to decrease with the distance from the tensile surface. It was calculated by Finite Element Modeling (FEM) that the (extreme) surface of the transformed bands was in tension during loading [17]. Therefore, the $t-m$ phase transformation was found to be accompanied by large changes in the stress field within and 
around the transformation bands and with residual stresses after unloading [13, 17]. Moreover, considering the high compressive stresses measured in the monoclinic phase after unloading [13], one may wonder as to the possibility to generate reverse transformation inside the band in bending, as was observed in pure compression [19].

In this context, even as phase transformation plasticity of Ce-TZP ceramics has been extensively explored, several aspects regarding transformation band's nucleation and growth mechanisms require further exploration. This paper thus addresses the following issues, focusing on different features of the $\mathrm{t}-\mathrm{m}$ transformation:

- How do the features (size, spacing, number, width, height and depth) of the transformation bands evolve during bending?

- What is the relationship between the transformation bands' nucleation and growth mechanisms and the dimensions of the beam (stress gradients inside the beam)?

- What are the effects of localized residual stresses on the transformation bands' nucleation and growth?

- Is there reverse transformation associated with the residual compressive stresses inside the bands after unloading?

Results regarding transformation plasticity mechanisms, such as band's nucleation and growth and stress relaxation between transformation bands, deserve also further discussion.

\section{Materials and methods}

\section{Material processing and initial characterization}

The studied material had a composition of 84 vol. $\% \mathrm{ZrO}_{2}\left(11 \mathrm{~mol} . \% \mathrm{CeO}_{2}\right), 8$ vol.\% of $\mathrm{Al}_{2} \mathrm{O}_{3}$ and 8 vol.\% of $\mathrm{SrAl}_{12} \mathrm{O}_{19}$, hereafter referred as $\mathrm{ZA}_{8} \mathrm{Sr}_{8} \mathrm{Ce}_{11}[10,20]$. It was chosen because of its propensity to display significant transformation-induced plasticity at room temperature and thus ductility before failure $[10,20]$. Processing has been fully described in [10]. In brief, the samples were produced by RISE (formerly SWEREA IVF) (Mölndal, Sweden) from spraydried powders of the composite, synthesized and provided by DAIICHI KIGENSO KAGAKU KOGYO CO. LTD (Osaka, Japan). The powders were shaped by Cold Isostatic Pressing (CIP) at $300 \mathrm{MPa}$ and pressure-less sintered at $1450^{\circ} \mathrm{C}$ for $1 \mathrm{~h}$ in air. The average size of zirconia grains was estimated from the linear-intercept method using 1.56 as correction factor. Zirconia grain diameter was of $0.9 \pm 0.4 \mu \mathrm{m}$. Alumina grains average diameter was measured directly on the micrograph, and was $0.3 \pm 0.1 \mu \mathrm{m}$. Strontium hexa-aluminate grains 
were present in the form of platelets of average length: $2.8 \pm 1.7 \mu \mathrm{m}$ and aspect ratio: $4 \pm 3$ ). Figures of the microstructure can be found in our previous work $[10,20]$. Density was determined by Archimedes' method using distilled water and three different weight measurements (dried mass, mass in water and mass submerged in water) according to the C373-88(2006) ASTM standard. Composites were almost fully dense ( $>99.9 \%$ of the theoretical density). Phase identification on sintered samples was performed by means of XRay Diffraction (X-ray Bruker D8 diffractometer, Billerica, USA) and showed that samples after processing were constituted of only tetragonal zirconia phase $\left(t-\mathrm{ZrO}_{2}\right)$, alumina $(\alpha-$ $\left.\mathrm{Al}_{2} \mathrm{O}_{3}\right)$ and strontium aluminate $\left(\mathrm{SrAl}_{12} \mathrm{O}_{19}\right)[10]$.

\section{Mechanical Testing}

4-point-bending (4PB) bars (length $(l)=30 \mathrm{~mm}$, width $(w)=4 \mathrm{~mm}$ and different thicknesses (t) equal to $0.5,1,2$ or $3 \mathrm{~mm}$ ) were machined by RISE (formerly SWEREA IVF) (Mölndal, Sweden) with a 16-micron diamond wheel. The samples were mechanically polished until 1 $\mu \mathrm{m}$ to allow optical characterization of the transformed zones and then manually and gently chamfered with care to avoid any possible micro-cracking or localized transformation from the edges of the samples due to stress concentrations. Both tensile and front surfaces were polished in order to quantify both the bands width and spacing on the tensile side and the bands' depth from the front side. After polishing and chamfering, the samples were annealed at $1200^{\circ} \mathrm{C}$ for 30 minutes in order to remove any residual stress or $t-m$ transformation associated with polishing [21, 22].

4PB tests were carried out using a universal hydraulic testing machine (INSTRON 8502, Nordwood, USA) equipped with a linear variable differential transformer (LVDT) for displacement measurements, at a cross-head speed of $0.1 \mathrm{~mm} / \mathrm{min}$. Both monotonic loading tests up to failure and loading/unloading tests were performed using a 10-21 mm jig. Standard samples were compared with indented samples. The indentations were performed on polished surfaces using a Vickers indenter (Buehler Micromet 5140, Illinois, USA) at a load of $0.1 \mathrm{Kgf}$. This load was chosen in order to get significant residual stresses (indents' size of $12.5 \mu \mathrm{m}$ in diagonal, larger than the material's microstructure) without creating defects larger than the critical size above which the samples would break before transformation-induced plasticity and estimated to be $\sim 100 \mu \mathrm{m}$ [20]. Indents were positioned on the tensile side of the specimens, on half of the samples' central part (i.e. half of the inner span length) and spaced every $200 \mu \mathrm{m}$ (the other half of the inner span being not indented for an accurate comparison 
of transformation bands, on the same sample). Two different types of samples were indented: one was tested directly after indentation whereas the second one was annealed $\left(1200^{\circ} \mathrm{C}\right.$ for 30 minutes) to remove the residual stresses related to the indentation before mechanical testing $[21,22]$. This procedure allowed appreciation of the impact of localized residual stresses on the transformation bands' nucleation mechanism.

All mechanical tests were performed at room temperature (RT) $\left(22 \pm 2^{\circ} \mathrm{C}\right)$ in air.

\section{Transformation bands analysis}

\section{Optical microscopy}

The transformation bands were characterized by optical light microscopy (ZEISS Axio-photo microscope, Oberkochen, Germany) using Nomarski interference contrast, on both tensile and front sides. For monotonic loading tests, samples were only observed after breakage whereas during loading/unloading tests samples were observed after each unloading step in order to analyse the bands' development. From the optical images, the transformation bands' parameters were quantified (number, width, spacing, depth and angle of the bands) for each loading step.

\section{Optical interferometry}

Transformation bands were characterized by white-light Vertical Scanning Interferometry (VSI) measurements using a S-Neox (Sensofar, Terrassa, Spain) 3D non-contact optical profiler machine, which combines confocal and interferometry techniques (lateral resolution of $0.26 \mu \mathrm{m})$. An objective of 10x with an acquisition area of $1.70 \times 1.42 \mathrm{~mm}^{2}$ was used with a step of $1.38 \mu \mathrm{m}$ on the two axes ( $\mathrm{x}$ and $\mathrm{y}$ ). Images of the samples were obtained after stitching using an overlapping parameter of $15 \%$. The acquired data were processed using MountainsMap Universal software ${ }^{\circledR}$ (DigitalSurf, Besançon, France). Images were also processed using both Image J [23, 24] and Fityk [25] software's for transformation bands' profiles analysis. Interferometry measurements enabled the topography of the surface to be generated, which was used here to determine the height of individual transformation bands.

\section{Finite Element Modeling (FEM)}

Finite Element Modeling (FEM) was performed with the ANSYS $®$ Mechanical APDL 2019 software (Ansys, Inc., Canonsburg, USA), in order to simulate the stress state inside and adjacent to transformation bands. To do so, a 4PB sample was modelled, with two different 
components that will mimic the matrix (untransformed regions) and the transformation bands (see Figure 1). 4PB tests were modelled in 2D (with coupled-field elements and plane strain assumption) and symmetry was applied to the sample to reduce the number of elements and calculation time. The sample length was set to $10.5 \mathrm{~mm}$ (corresponding to half the outer-span of the $4 \mathrm{~PB}$ experiments), the sample thickness to $3 \mathrm{~mm}$ and the spans location were fixed at $\mathrm{x}$ $=0$ and $5.5 \mathrm{~mm}$ along the sample length $(x)$. The transformation bands were modelled as triangles with $0.2 \mathrm{~mm}$ in width and $1 \mathrm{~mm}$ in depth. Three transformation bands were modelled along the sample length at $x$ position equal to $7.5,9$ and $10.5 \mathrm{~mm}$.

Both regions had the same elastic behaviour, but, to account for the volume expansion associated to the $t-m$ transformation, a different thermal expansion coefficient was chosen. The sample was first loaded to a certain displacement and then to a thermal loading to induce volume expansion in the transformation bands. The applied displacement $\mathrm{U}_{\mathrm{y}}$ of the inner support was fixed to $0.07 \mathrm{~mm}$ (more precisely $68 \mu \mathrm{m}$ ) in order to obtain a maximal applied tensile stress of $500 \mathrm{MPa}$, in line with values reached during $4 \mathrm{~PB}$ experiments. The thermal loading was thus applied so as to simulate the volume expansion due to the $t-m$ phase transformation of the zirconia phase in the composite. For this purpose, an arbitrary $1{ }^{\circ} \mathrm{C}$ increase in temperature was applied, the matrix had a null linear thermal-expansion coefficient $\left(\alpha_{\mathrm{m}}=0\right)$, while the transformation bands had a linear thermal-expansion coefficient $\alpha_{t b}$ of:

$$
\alpha_{t b}=\frac{1}{3} \times\left(\frac{\Delta V}{V}\right)_{t-m} \times V_{f_{\text {zirconia }}} \times V_{f_{\text {monoclinic }}}
$$

Where $\left(\frac{\Delta V}{V}\right)_{t-m}$ is the volume expansion associated to the $t-m$ transformation (taken as $4 \%$ in line with most published data $[11,12,26]), V_{f_{\text {zirconia }}}$ the volume fraction of zirconia in the composite (84\%) and $V_{f_{\text {monoclinic }}}$ the volume fraction of zirconia grains transformed towards the monoclinic symmetry inside the bands. The volume content of monoclinic phase in the bands was estimated in another paper [27] and was taken here as $20 \%$. $\alpha_{t b}$ was thus set to $\alpha_{t b}=0.00224$.

\section{Results}

\section{1- Transformation bands nucleation and growth with loading}


Figure 2 illustrates a load-displacement curve during successive loading/unloading 4PB tests, for a $1 \mathrm{~mm}$-thick sample. The sample shows visible permanent displacement (plastic deformation) associated with the $t-m$ transformation. The onset of non-linearity occurs at a load of $\sim 100 \mathrm{~N}$, corresponding to a stress of $\sim 370 \mathrm{MPa}$ calculated following the standard equation:

$$
\sigma=\frac{3}{2} F \frac{(L-l)}{w t^{2}}
$$

with $F$ the applied load, $L$ and $l$ the outer and inner spans lengths respectively, $w$ the sample's width and $t$ its thickness. As soon as plasticity occurs (after the onset of transformation), stresses calculated from equation (1) are obviously not entirely correct [20]. However, 'calculated stresses' (from eqn. 1) given below are an indication of the applied external stresses. In the general case, the onset of plasticity detected in the load-displacement curves was fully consistent with the nucleation of the first $t-m$ transformation band(s). In few of the samples, one small and very thin band, but not going through the entire width of the sample, was visible before the appearance of a non-linearity in the load-displacement curves. Such bands were probably localized on stress concentration sites (initiating from edges of the sample or sometimes from a defect). However, they only represented a very minor fraction of observed transformation bands with a minor effect on the analyzes.

Figure 3 shows optical microscopy images obtained with Nomarski contrast on a 3mm-thick sample during multiple loading/unloading cycles. The first transformation bands were found to appear at a load of $\sim 800 \mathrm{~N}$, corresponding to a calculated stress of $\sim 370 \mathrm{MPa}$. It was found that the bands started to form on the tensile side of the samples and then proceeded through the sample (i.e. from the tensile side toward the neutral axis). The number of bands increased with applied load until a saturation at loads close to the load to failure. Newly formed bands always appeared as very thin (approximately $10 \mu \mathrm{m}$ ) and some of them increased in width with increasing load. Specimen fracture occurred from one of the widest bands (which was not necessarily from the very first band initiated, e.g. in Figure 3, from the $10^{\text {th }}$ band in order of appearance). The spacing of the bands became more regular and constant at loads close to the load to failure (saturation), in agreement with the fact that the number of bands also saturated at high loads.

Figure 4a shows the optical Nomarski images of two different bands, the first one and the $10^{\text {th }}$ band that appeared on the tensile surface of a 3-mm sample at two different loads (918 N 
(436 MPa) and $1056 \mathrm{~N}(501 \mathrm{MPa})$ ). It shows that band number 1, even though it was the first one to nucleate, did not increase in width with increasing load whereas band number 10 widened substantially as the load increased, eventually leading to fracture at $1096 \mathrm{~N}$. The width of four different bands $\left(1^{\text {st }}, 2^{\text {nd }}, 10^{\text {th }}\right.$ and $16^{\text {th }}$ in order of appearance) for different loads ranging from $832 \mathrm{~N}$ to $1094 \mathrm{~N}$ (i.e. $395 \mathrm{MPa}$ to $519 \mathrm{MPa}$ ) are shown Figure 4b. It shows that both bands number 2 and 10 widened whereas the bands number 1 and 16 did not significantly increase in width with increasing load. Therefore, some transformation bands widen more than others, regardless their order of appearance on the tensile surface of the beam.

The main features of bands observed on the tensile side (number, width and spacing) of a standard specimen of $3 \mathrm{~mm}$ thickness are shown in Figure 5 (black squares). Figure 5a quantifies the number of bands as a function of the applied calculated stress. The bands start to form at a stress of $\sim 370 \mathrm{MPa}$. The number of bands then increases with increasing applied stress until reaching saturation at $\sim 500 \mathrm{MPa}$, close to the load to failure (Figure 5a). The width of the bands as a function of the applied calculated stress is shown in Figure 5b. The width of the bands increases with increasing the stress and the standard deviation (SD) also drastically increases. This can be explained by two different reasons: (i) First of all because newly formed bands (irrespective of the stress they initiate at) are always very thin, while bands formed at lower stresses that have grown are also present. (ii) Secondly: as shown Figures $4 a$ and $b$, some bands widen more than others during loading. Figure $5 \mathrm{c}$ shows the spacing of the bands as a function of the calculated applied stress. The spacing of the bands decreased with increasing stress, until reaching a clear saturation at stresses higher than $\sim 450$ $\mathrm{MPa}$. When looking at the spacing's variation with increasing load, the saturation is even more pronounced.

\section{2- Effect of indentations on transformation bands' nucleation}

Figure 6a and b show the optical images obtained with Nomarski interferences of $3 \mathrm{~mm}$-thick samples at a load of $960 \mathrm{~N}(\sim 450 \mathrm{MPa})$, with indents on half of the inner span length. The sample shown in Figure 6a was not annealed after indentation whereas the sample shown in Figure $6 \mathrm{~b}$ was annealed after indentation to remove the residual stresses associated with the indentation. Figure 6a shows that all observed transformation bands initiated from indents. However, not all the indents led to the development of a complete band across the entire 
width. More precisely, a limited transformation could occur from the corners of the indentations, without leading to the formation of a well-developed band throughout, as illustrated in the insert in Figure 6a. It was found that the first small bands created were localized at indents and normal to the tensile loading direction. These very small bands were found to initiate and grow (typically to 3 to 5 times the size of the transformed region about the indent $(28.3 \pm 0.7 \mu \mathrm{m}$ and $112.3 \pm 48 \mu \mathrm{m}$ for the transformed zone region around the indent and the initiated bands expansion zone respectively)) from all the indents' corners but not all subsequently propagated as the load was increased (Figure 6a - insert). The number and spacing of the bands were comparable on the half of the sample with indents and on the other half without indents, the only difference being that the bands formed on the indented side were always located on an indent (Figure 6a). In Figure 6b, where the residual stresses were removed by thermal annealing, the number and spacing of the bands was also comparable on both sides with and without indents but this time the bands did not initiate from the indents and no transformation was visible at the indent's corners. Figures $5 \mathbf{a}$, b and c also show the number, width and spacing of the bands respectively as a function of the calculated stress for three different samples (without indents, with indents and with indents and annealing) indicating that no significant differences are observed in the transformation bands' features between the three samples (standard and indented).

\section{3- Effect of beam thickness on transformation bands' nucleation mechanisms}

Figures 7a, b, c and d show optical microscopy images using Nomarski contrast of 4 different samples (thickness ranging from $0.5 \mathrm{~mm}$ to $3 \mathrm{~mm}$ respectively) at a calculated stress of $450 \mathrm{MPa}$. It shows that at the same value of stress, the 4 samples exhibit different transformation band features (number, width and spacing respectively). The number of bands is clearly dependent on the sample thickness with a higher number of bands for thinner samples. For 1, 2 and $3 \mathrm{~mm}$ thick samples, transformation bands show a typical parallel-band shape. For the thinnest sample $(0.5 \mathrm{~mm}$ thick), bands are not all extending across the entire width of the sample and may appear as partial irregular bands (Figure 7a). This may be related to the very small thickness of the sample $(0.5 \mathrm{~mm})$, possibly leading to a more inhomogeneous stress distribution (even with care taken to obtain flat and parallel surfaces). Considering the width of the bands at $450 \mathrm{MPa}$, it increases with the thickness of the beams (Figure 7) up to 2-mm thick sample (Figure 7a, b and c) and then decreases (Figure 7d). 
The 2mm-thick broke at $450 \mathrm{MPa}$ and the bands appear to have widened and reached saturation in width before failure. However, the 3mm-thick sample (Figure 7d), which shows bands of smaller width, was just at the beginning of plasticity at $450 \mathrm{MPa}$ while the sample broke at a slightly higher calculated stress value (520 MPa) with limited plastic strain, possibly explaining why the bands are not as wide compared to the other samples.

Figure 8a shows the number of bands as a function of the thickness of the beam (average values at breakage for all the samples). It shows that the number of bands is decreasing with increasing sample's thickness, fitting quite well with a $1 / t$ relationship (with $t$ the thickness of the beam) and in agreement with Figure 7. The spacing of the bands as a function of the sample thickness is shown in Figure 8b. A clear increase of the spacing of the bands is visible with increasing beam thickness, following a linear relationship (i.e. spacing $\sim t$ ), in line with the observation that the spacing is inversely proportional to the number of bands. Figure $8 \mathrm{c}$ shows the width of the bands as a function of sample thickness (values here measured at breakage). The bands' width is on average comparable for all the samples, however, assuming that some bands widen more than others (Figure 4) and taking into account therefore the widest bands, a slight increase of the width is visible with increasing beam thickness. The band depth, as measured on the front side, is shown in Figure 8d as a function of the beam's thickness. The depth of the transformation bands is clearly increasing with increasing thickness of the beam.

\section{4- Geometrical features of the bands}

As can be seen in Figure 9a, transformation occurs in the form of regularly-spaced parallel bands on the tensile side of bending bars after testing, whereas on the front size the bands develop in the shape of "wedges" (triangles). This wedge-shape is clearly visible in Figure 9c, showing that the bands also exhibit volume (uplift) on the front side (uplift in all directions, both on the front side and on the tensile side). However, the uplift of few hundreds of nanometers on average (Figures $9 \mathrm{~b}$ and $9 \mathrm{c}$ ) is clearly very small compared to the depth of the bands (hundreds of microns) (Figure 9c). Also, the larger (and deeper) the band, the higher the associated uplift.

\section{5- Finite Elements Analysis of stresses induced by transformation bands}


The variation of the displacement, $U_{y}$, along the sample length $(x)$, for a depth value, $y$, equal to $3 \mathrm{~mm}$ (top, tensile surface), obtained by Finite Element Modeling (FEM) and shown in Figure 10a, confirmed the presence of small uplifts associated with each band and related to the transformation and associated volume expansion. The uplift observed from FEM simulations is in the same order of magnitude as the one measured by optical interferometry (Figures 9b) for the deepest bands observed (400 nm uplift) for this sample thickness. It is interesting to note that, for a given applied displacement of the loading support, the deflection of the beam is slightly but significantly greater after the volume expansion of the bands (see Figure 10b of the outlined area of Figure 10a). This additional displacement accounts for the plastic deformation of the beam. The evolution of $\sigma_{x x}$ across the thickness of the beam, $y$ ( $\mathrm{y}=$ 0 on the compressive side and $y=3 \mathrm{~mm}$ at the tensile surface) is presented in Figure 10c, after elastic loading and following volume expansion. Tensile stress concentrations are present at the tip of the transformation bands and very near the external surface of the transformation bands. These tensile stresses, especially with increased loading, may trigger the further growth of individual bands. Apart from the tip region and the very near surface, as observed Figure 10c, the bands are mainly under compression. Lastly, Figure 10d shows the evolution of $\sigma_{x x}$ along the sample length $(x)$, along the tensile surface. It is interesting to observe that the surface of the transformation bands is in tension, while stress-shielding (that is stress-reduction) occurs adjacent to the bands, in the untransformed regions.

\section{Discussion}

\section{1- Transformation bands' nucleation and growth}

\section{1-1 Influence of pre-existing defects and residual stresses}

Ductility of some Ce-TZP ceramics during bending has already been clearly related to the formation of $t-m$ transformation bands $[5,8,11,12,13,15-16]$. It has been shown that transformation bands may manifest either as load drops visible on Stress-Strain (S-S) curves during bending tests or as smooth hardening-like responses $[5,8,11,12,13,15-16]$. In this work, the behavior is clearly of the latter form with a smooth strain-stress curve and an apparent hardening effect without pop-in events or load-drops (Figure 1). This is in contrast with some previous results obtained for $12 \mathrm{~mol} \% \mathrm{Ce}$-TZP materials and mentioned in the 
literature $[5,8,11,12,13,15-16]$ and is probably related to the homogeneity of the present

material, associated with a very fine microstructure and the presence of $2^{\text {nd }}$ and $3^{\text {rd }}$ phases (see typical microstructures in [20]). Moreover, this is complemented by the removal of the residual stresses associated with machining and polishing (via annealing) and chamfering of the samples. Indeed, annealing and/or chamfering processes were not always performed in previous studies $[5,8,11,12,13,15-16]$, which could have led to the presence of localized stress concentrations and premature transformation. In other words, the sudden or progressive onset of plasticity is likely to be related to the processing and finishing conditions. The observed progressive transformation-induced plasticity was here associated with visible transformation bands that initiate at a given stress $\left(\sigma_{c}^{t-m}\right)$ and then grow in number, width, depth and height with increasing applied stress, illustrating a nucleation and growth behavior. It was found that the bands started to form on the tensile side of the samples and then proceeded through the sample (i.e. from the tensile side toward the neutral axis), in agreement with Liu [28]. Rauch et al. [16] suggested the presence of two types of transformation features in their work, namely associated with general plasticity ruled by the applied stress plus additional autocatalytic spontaneous-transformation. Our observations confirm the presence of an autocatalysis phenomenon with the generation of thin bands across the tensile surface at a specific tensile stress, which then grow in width in a stable manner with increasing stress leading to an increased plastic strain.

Indentations and in particular the indentation-residual-stress field appear to play the role of pre-existing sites of nucleation, since small bands propagate from all indentation corners in tension for un-annealed specimens (Figure 6a). These observations show initial stable transformation band extension to a size of $\sim 100 \mu \mathrm{m}$ prior to the unstable extension of some bands, clearly showing the role of the residual tensile stresses existing about the indentation induced transformation. That is, the residual stresses about the indentation, which decline with radial distance from the edge of the transformation, along with the applied flexure global tensile stress result in the initial stable band extension. The observation of indentation nucleated bands are in agreement with previous results $[16,18]$ and confirmed that any heterogeneity in the stress field (stress concentration zones) can initiate a transformation band. Indents themselves, after annealing, do not act as preferential nucleation sites (Figure 6b). Indeed, as the angle of the residual indentation impression pyramid is very shallow $(<2 \mu \mathrm{m}$ with $0.1 \mathrm{Kgf}$ Vickers indent), the annealing led to removal of the residual stresses and therefore to minimal stress concentration at the indent corners. 
It is also interesting to emphasize that even if the number of nucleation sites for transformation bands to occur was larger when indentations were performed, the final bands' number and their size was the same as without any pre-existing sites. Transformation-induced plasticity was thus the same with or without the presence of additional indentation preexisting nucleation sites. In the case of as-indented samples, some of the bands initiated at the corner of the indents did not extend, even with substantial increase in load. This does indicate that some form of stress relaxation occurs between existing bands as will be explored in a following section and already noted with the help of Finite Element Analysis.

\section{1-2 Geometrical features of the bands}

Regularly spaced transformation bands are visible on the tensile side of 4PB tested specimens (Figure 9), which is in agreement with previous results on Ce-TZP ceramics observed after bending $[5,14,15]$. On the front side, the bands exhibit a wedge shape with visible uplifts. FEA confirmed that the uplift was directly related to the volume expansion associated with the $t-m$ transformation of a portion of the zirconia grains inside the bands. Only tetragonal grains with a preferred orientation related to the applied stress may transform into the monoclinic symmetry ( $20-30 \%$ of the grains only) $[4,29]$.

The angle $\alpha$ of the triangle-shape-bands on the front side (Figure 11c) can be easily expressed, by simple trigonometry, as follows:

$$
\operatorname{Tan}\left(\frac{\alpha}{2}\right)=\frac{w}{2 D}
$$

with $w$ the width of the band and $D$ the depth. Therefore, by plotting the width of the bands as function of the depth, the variation of the angle can be evaluated for each individual band. This is presented in Figure 11, where both the width and the depth of the bands are normalized to the thickness of the beam. It can be seen that on average, there is a linear relationship between the width and the depth of the bands, whatever the thickness of the beam. In other words: the wider the bands, the deeper they are. No real difference is seen in terms of bands' angle $(\alpha)$ between $1 \mathrm{~mm}$ and $3 \mathrm{~mm}$-thick samples, with an average value between 7 and $8^{\circ}$. However, looking at each band individually, there is a large dispersion of the results with some thin bands that extend deep in the sample while some wider bands do not propagate so deeply, which may confirm that the geometry of the bands is not precisely constant (that is the angle varies from one band to another, as will be further discussed). 
Figure 9b shows VSI image of a 3mm-thick sample with related profiles of both a thick band (profile 1) and a thin band (profile 2), the thinner band being smaller in terms of height than the thicker one. Moreover, wider bands show a much more visible saturation with flatter gradients whereas thin bands have steeper gradients and almost no saturation. This "saturatedband-shape" is schematically illustrated in Figure 9c. This has been confirmed when looking at a 3mm-thick sample (not shown here), which showed a visible linear relationship between the height and the width of its bands. In other words: the wider the bands, the greater the uplift, which is in agreement with the volume change associated to the transformation, illustrating a geometrical aspect of the bands.

Results from Figures $4 \mathrm{a}$ and $\mathbf{b}$ show that some transformation bands widen much more than others during loading, with no clear relation to the order of appearance of the band. This result is confirmed in Figure 5b when looking at the SD values of the width of the bands for the different sample thicknesses, showing that as the load increased, the SD became larger, as some bands widened considerably whereas other bands remained very narrow. This was also confirmed in Figure 11 when looking at the angle of each band individually. For a comparable band's depth, it was found that the angle was not constant from one band to another (whatever the beam's thickness), with very thin bands (small angle) and very wide bands (large angle). In agreement with these results, we have shown that the bands are initially very narrow and that they show limited extension in the depth direction with increasing load. However, they show a $\sim 4$ to 5 times increase in width (Figure 5b). The bands therefore appear to be initially narrow because of an initial instability during their formation, which causes them to propagate very quickly and extend deeper into the beam than anticipated from applied elastic stresses. Then, once they reach a more "stable" state, they are able to further develop and-increase in width. FEM confirmed that tensile stresses were found to be present at the tip of transformation bands, which may trigger their initial rapid propagation towards the neutral axis (Figure 10b). Once the bands are formed, they cannot readily grow deeper because the reducing tensile and then compressive stress beneath the neutral axis of the beam prevents their expansion inside the beam (stress $<\sigma_{c}^{t-m}$ ).

\section{1-3 Effect of beam's thickness}


Figures 7 and 8 a have shown that the number of bands was inversely proportional to the thickness of the beam and therefore the spacing proportional to the thickness of the sample. When looking at the variations of the width vs depth of the bands normalized to the thickness of the beam (Figure 11), it can be seen that for the thin samples (e.g. $1 \mathrm{~mm}$ thick), the maximum depth/thickness ratio is $\sim 0.5$ whereas for the thick samples (e.g. $3 \mathrm{~mm}$ thick) this ratio is $\sim 0.3$. This means that for the thin samples, the bands propagated until the neutral axis (position $=0.5$ of the beam thickness), whereas for thick samples, they only propagated until 0.3 of the beam's thickness. This is in agreement with previous results showing that the wedge-like shape bands, mostly with samples that displayed a load drop with band nucleation, were found to exhibit a tip close to the neutral axis of the beam after flexure of $12 \mathrm{~mol} \% \mathrm{Ce}$ TZP ceramics [14-16]. Extension of the bands even to 0.3 of the beam thickness is surprising as the tensile stress at the tip of the band is reduced by $60 \%$ from the tensile surface, which is well below the nucleation stress. The fact that such bands are even deeper in thinner beams suggests that these bands appear to have extended well beyond where they would have extended in equilibrium, which may imply that they require a slight overload to initiate but then rapidly propagate to beyond the equilibrium stress. This concept is further supported by the fact that these bands display minimal further growth in depth, despite substantial widening (up to 5 times), upon increasing loading. As a consequence, many more bands are generated on thin samples than on thick samples, as observed in Figure 7. This was confirmed when normalizing the depth of the bands to the thickness of the sample, where it was found that the average depth was higher for the thin samples compared to the $3 \mathrm{~mm}$ thick samples $(212 \pm 79$ $\mu \mathrm{m}$ and $112 \pm 23 \mu \mathrm{m}$ for the $1 \mathrm{~mm}$ and $3 \mathrm{~mm}$ thick samples respectively - not shown here). When looking at the transformation bands' features, it was also found that the width of the bands increased slightly with the beam's thickness. On average, the bands' width was comparable from one sample to another (average value of $\sim 25 \mu \mathrm{m}$ ) (Figure 8c). However, for the 3mm-thick samples, a very large SD is observed, leading to the maximum bands' width as large as $120 \mu \mathrm{m}$ (Figures $\mathbf{8 c}$ and 11). This large scatter observed for the $3 \mathrm{~mm}$-thick sample is mainly associated with the fact new bands are still initiating during increasing load whereas existing bands continue to widen, combined with the fact some bands widen more than others (Figure 3). If the highest band width's value is taken into account, it is clear that a widening of the bands is observed from $1 \mathrm{~mm}$-thick samples to $3 \mathrm{~mm}$-thick ones, in agreement with the previous statement (i.e. on thin samples, a larger number of thin bands are generated whereas on thicker sample, fewer but wider bands are generated to accommodate the plastic strain). 


\section{1-4 Stress shielding effect}

Another important aspect of the transformation bands' nucleation is the effect of each individual band on the neighboring bands. Figure 12a shows an optical microscopy image with Nomarski contrast of the side view of a $3 \mathrm{~mm}$-thick sample after 4PB tests. Both thin (black arrows) and wide bands are clearly visible, with a constant spacing between the wider bands, as observed previously (Figures 3, 7d and 9a). As mentioned earlier, as soon as the material reaches the stress necessary to induce the $t-m$ phase transformation $\left(\sigma_{c}^{t-m}\right)$, transformation bands start to appear. On further loading, some of the bands will then enlarge and result in the formation of localized "plastic-hinges" within the tensile portion of the beam that lie between substantial regions of retained elastic behavior. These "plastic-hinges" distort the tensile stress field from that of an elastic beam and would appear to generate a stressshielding zone around them (probably in the order of their respective depth (Figures 12a and b)). Such hypothesis has been confirmed by FEM (Figure 10c), as significant stressrelaxation was simulated when the wedge-like bands arepresent. This stress-shielding around transformation bands is similar in its concept (although its magnitude is lower) to the stressshielding around cracks, which leads to multiple, regular cracking in Ceramic Matrix Composites [30]. Finally, because of this shielding zone, narrow bands adjacent to wider bands are unable to expand. Only outside the stress shielding zone can another band develop, which is also in agreement with previous work on martensite $\mathrm{Fe}-\mathrm{Ni}-\mathrm{C}$ steel under bending [14]. This implies that the spacing and the depth of the bands are roughly equal, as the spacing of the bands is dictated by their depth (shielding zone scaling with the depth of the large bands) (Figure 12b). This seems to be the case, as illustrated in Figure 12c. It is also the reason why the bands that nucleated on some of the indentations do not develop into complete bands across the tensile surface and why the spacing is similar with or without indentations.

\section{2- Reverse transformation}

After breakage and unloading, some bands were found to be incomplete and display "missing parts" (Figure 7c). This finding was observed on almost all the samples whatever their thickness (Figure 13), and always after breakage only. This phenomenon could be related to a reverse transformation (i.e. where the band is no more visible, the grains have transformed 
back to the tetragonal phase). To confirm such hypothesis, a sample was found to show this reverse transformation after breakage only, whereas the transformation band was fully developed at lower load values, as seen in Figures 13a and b. This confirms that the "broken" transformation bands are related to a possible reverse transformation and not to microstructural features of the material (higher ceria content and therefore lower transformability or more aluminates hindering the transformation for example [11, 12]). However, when reloading a tested sample with bands placed in compression by turning it over on the 4-point bend jig, it was found that no reverse transformation was observed even after compression at loads as high as $1000 \mathrm{~N}$ ( $\sim 480 \mathrm{MPa}$ ) (not shown here). This indicates that reverse transformation cannot be produced by loading in compression and that the disappearance of the bands related to spontaneous reverse transformation only occurs upon failure. During unstable fracture, there is a considerable release of energy and formation of stress waves, (as with an earthquake), that radiate from the extending crack region. Because of the different speeds of theses waves (Rayleigh versus compressional and shear), plus reflection of the compression and shear within the sample, the magnitude of these stresses at specific locations can be greatly increased, which potentially may result in localized compressive stresses sufficient to reverse the transformation [31]. Moreover, such reverse transformation was previously observed by Liu and Chen [19] in a 12 mol\% Ce-TZP but in uniaxial compression only and at very high applied stresses.

\section{3- Limits of the study}

\section{3-1 Tests after unloading}

Results obtained here are in good agreement with previous studies from the 80's and 90's [5, $8,11-19,32$ ], with only some differences observed in terms of bands' aspect and autocatalysis phenomenon, which were absent here most likely because of a combination of several factors: a finer microstructure and second phases added to the composites actually being studied, combined with removal of residual stresses after machining, polishing and gentle chamfers preparation. However, most of the observations (as those obtained in previous works) were obtained on beams after unloading (or breakage). This suggests that in-situ experiments should be an interesting approach to understand better the transformation plasticity and band's 
nucleation-growth mechanisms during loading (i.e. in situ 4PB tests combined with Optical interferometry and Raman monitoring for example).

\section{3-2 Tension vs bending}

Previous results on the same material but in tension have shown that significantly higher plastic strains could be reached during tensile tests on cylindrical, dog-bone shape samples, when compared to bending [20]. A major question then arises: why is plastic strain at failure higher in tension than in bending? We believe that this is because the bands are less geometrically constrained in uniform tension than in bending. Indeed, in tension, much more plastic strain could be reached as the stress field is homogeneous (the regions between bands are not shielded by the presence of the transformation bands, as it is the case in bending). Such outcomes indicate that the transformation bands' generation, and therefore, the final plastic strain reached by the material, are constrained by the 4PB loading configuration. Even though efforts were made to prepare and carefully polish tensile dog-bone shape specimens, it was not possible to clearly observe the transformation features on these cylindrical samples, since the polishing was insufficient to reveal the transformation bands by optical interferometry [20]. For the future, it could be interesting to analyze the shape of the transformation during pure-tensile test, as in this load configuration, no geometric localization process is present, which appears to lead to the observed higher extent of plasticity [20].

All these results may re-open the discussion on transformable Ce-TZP materials and raise the question as to how to achieve a greater extent of plasticity in these materials, which may be constrained by geometrical feature, macroscopic stress state and stress-shielding phenomena.

\section{Conclusions}

A Ceria-doped zirconia-based composite was tested in bending with different sample geometries. Experimental analysis of the transformation bands' characteristics by optical microscopy and interferometry has highlighted the following as the main aspects of the transformation plasticity and especially the impact of both residual stresses and sample's geometry (stress state inside the beam) on the transformation bands' nucleation and growth mechanisms: 
1- When the material reached a stress $\sigma=\sigma_{c}^{t-m}$, localized parallel transformation bands started to develop on the tensile side of the beam, and then proceeded inward from the tensile side toward the neutral axis.

2- Transformation bands grew in number, width, height and depth with increasing the load showing a nucleation and growth process, which accommodates the applied strain.

3- Some bands were found to widen more than others, irrespectively of their order of appearance.

4- Residual stresses play a significant role in the nucleation of the transformation bands but not on the number of bands formed which is only geometrically determined.

5- The number of bands follows a $1 / t$ relationship with $t$ the thickness of the beam, with a saturation of the band's number occurring prior to failure.

6- Nucleation of the bands was found to be related to: (i) geometry (stress field inside the sample), (ii) a shielding effect from already existing bands and (iii) stress concentration at the surface (such as poor surface finishing, pre-existing defects or indentation).

7- All plastic displacement is accommodated by transformation bands (i.e. transformation bands are acting as "plastic hinges"). Stress relaxation (stress-shielding) occurred between the transformations bands, explaining the regular spacing of the bands and their relation to the beam thickness.

8- Reverse transformation occurs during failure but the understanding of this phenomena requires further investigation.

9- A geometrical localization process of the transformation bands was highlighted within this study and was found to limit the extent of plasticity that the material could reach in bending.

\section{Acknowledgements}

The research leading up to these results was undertaken in the framework of the LONGLIFE project (http://www.longlife-project.eu) funded by the European Community's Seventh Framework Program (FP7/2007-2013) under the grant agreement n. 280741 and SISCERA project (http://siscera-project.eu) also funded by E.U. (H2020-FTIPilot-2016, grant agreement n. 737954). The research effort conducted by our other partners in the field of powder synthesis and processing is deeply appreciated and acknowledged. In particular, we warmly thank our colleagues and friends from Politecnico di Torino, Marta Fornabaio, Paola Palmero, 
Laura Montanaro, from RISE (formerly SWEREA IVF), Erik Adolfsson, and Doceram AG, Tobias Fuerderer and Sven Schomer. Prof. Mike Swain was present at INSA-Lyon as a visiting Professor in the course of this specific work. The authors acknowledge the support of the institute for providing this temporary position and for the associated financial support.

\section{References}

[1] Garvie R. C., Hannink R. H. J., Pascoe R. T., Ceramic Steel?, Nature, 1975, vol. 258, no. 5538, pp. 703-704.

[2] Claussen N., Microstructural, design of Zirconia-Toughened Ceramics (ZTC), In: Claussen N, Ruhle M, Heuer AH, editors. Advances in Ceramics, Vol. 12. Science and Technology of Zirconia 11. Columbus OH: American Ceramic Society, 1984, pp. 325-351.

[3] Heuer A. H., Transformation toughening in $\mathrm{ZrO}_{2}$-containing ceramics., J Am Ceram Soc., 1987, vol. 70, no.10, pp. 689-698.

[4] Mamivand M., Asle Zaeem M., El Kadiriab H., Phase field modeling of stress-induced tetragonal-to-monoclinic transformation in zirconia and its effect on transformation toughening, Acta Mater., 2014, vol. 64, pp. 208-219.

[5] Grathwohl G., Liu T., Crack Resistance and Fatigue of Transforming Ceramics: II, $\mathrm{CeO}_{2}-$ stabilized tetragonal $\mathrm{ZrO}_{2}$, J. Am. Ceram. Soc., 1991, vol. 74, pp. 3028-3034.

[6] Gogotsi G. A., Zavadaa V. P., Swain M. V., Mechanical Property Characterization of a 9 mol\% Ce-TZP Ceramic Material -I. Flexural Response, J Eur Ceram Soc., 1995, vol.15, no.12, pp.1185-1192.

[7] Fett T., Munz D., Influence of time-dependent phase transformations on bending tests, Mat Sci Eng A-Struct., 1996, vol. 219, no.1-2, pp. 89-94.

[8] Rauchs G., Fett T., Munz D., Oberacker R., Tetragonal-to-monoclinic phase transformation in $\mathrm{CeO}_{2}$-stabilised zirconia under uniaxial loading. , J Eur Ceram Soc., 2001, vol.21, no.12, pp. 2229-2241.

[9] Palmero P., Fornabaio M., Montanaro L., Reveron H., Esnouf C., Chevalier J., Towards long lasting zirconia-based composites for dental implants. Part I: Innovative synthesis, microstructural characterization and in vitro stability, Biomaterials, 2015, vol.50, pp. 38-46. [10] Reveron H., Fornabaio M., Palmero P., Fürderer T., Adolfsson E., Lughi V., Bonifacio A., Sergo V., Montanaro L., Chevalier J., Towards long lasting zirconia-based composites for dental implants: Transformation induced plasticity and its consequence on ceramic reliability, Acta Biomater., 2017, pp. 423-432. 
[11] Reyes-Morel P. E., Chen I.W., Transformation Plasticity of $\mathrm{CeO}_{2}$-Stabilized Tetragonal

Zirconia Polycrystals: I, Stress assistance and autocatalysis, J. Am. Ceram. Soc., 1988, vol. 71, no. 5, pp. 343-353.

[12] Reyes-Morel P. E., Cherng J.S., Chen I.W., Transformation Plasticity of $\mathrm{CeO}_{2}$-Stabilized Tetragonal Zirconia Polycrystals: II Pseudoelasticity and Shape Memory Effect, J. Am.

Ceram. Soc., 1988, vol. 71, no. 8, pp. 648-657.

[13] Sergo V., Clarke D. R., Pompe W., Deformation bands in Ceria-stabilized

Zirconia/Alumina: I, Measurement of internal stresses, J. Am. Ceram. Soc., 1995, Vol. 78, pp. 633-640.

[14] Baur A. P., Cayron C., Variant Selection in Fe-20Ni-1.8C under Bending, Crystals, 2018, pp. 1-9.

[15] Hannink R. H. J., Swain M. V., Metastability of the Martensitic Transformation in a 12 mol\% Ceria-Zirconia Alloy: I, Deformation and Fracture Observations, J. Am. Ceram. Soc., 1989, Vol. 72, no. 1, pp. 90-98.

[16] Rauchs G., Fett T., and Munz D., Calculation of Autocatalytic Phase Transformation Zones in Cracked and Uncracked Zirconia Ceramics, Inter. J. of Fracture, 2002, vol. 116, pp. $121-140$.

[17] Sergo V., Schmid C., Meriani S., Evans A. G., Mechanically Induced Zone Darkening of Alumind Ceria-Stabilized Zirconia Composites., J. Am. Ceram. Soc., 1994, Vol. 77, pp. 29712976.

[18] Stump D. M., Autocatalysis: the self-induced growth of martensitic phase transformations in ceramics, Acta. Metall. Mater., 1994, vol. 42, no. 9, pp. 3027-3033.

[19] Liu S.Y., Chen I.W., Plasticity induced Fatigue Damage in Ceria-Stabilized Tetragonal Zirconia Polycrystals, J. Am. Ceram. Soc., 1994, Vol. 77, pp. 2025-2035.

[20] Chevalier J., Liens A., Reveron H., Zhang F., Reynaud P., Douillard T., Preiss L., Sergo V., Lughi V., Swain M., Courtois N., Fourty years after the promise of « ceramic steel? »: zirconia-based composites with a metal-like mechanical behavior, J. Am. Ceram. Soc., 2020, vol.103, pp. 1482-1513.

[21] Chevalier J., Olagnon C., Fantozzi G., Study of the residual stress field around Vickers indentations in a 3Y-TZP, J. Mater. Sci., 1996, vol. 31, pp. 2711-2717.

[22] Chintapalli K.R., Rodiguez A., Marro F., Anglada M., Effect of sandblasting and residual stress on strength of zirconia for restorative dentistry applications, J. Mech. Behav. Biomed. Mater., 2014, vol. 29, pp. 126-137. 
[23] Abramoff M., Magalhaes P., Ram S.J., Image processing with ImageJ, J. Biophotonics Int., 2004, pp. 36-42.

[24] Schindelin, J., Arganda-Carreras I., Frise E., Kaynig V., Longair M., Pietzsch T., Preibisch S., Rueden C., Saalfeld S., Schmid B., Fiji: An open-source platform for biologicalimage, Nat. Methods, 2009, pp. 676-682.

[25] Wojdyr M., Fityk: a general-purpose peak fitting program, J. Appl. Crystallogr, 2010, pp. $1126-1128$.

[26] Deville S., Guénin G., Chevalier J., Martensitic transformation in zirconia Part I. Nanometer scale prediction and measurement of transformation induced relief, Acta Mater., 2004, vol. 52, no. 19, pp. 5697-5707.

[27] Liens A., Reveron H., Douillard T., Blanchard N., Lughi V., Sergo V., Laquai R., Müller B. R., Bruno G., Schomer S., Fürderer T., Adolfsson E., Courtois N., Swain M., Chevalier J., Phase transformation induces plasticity with negligible damage in Ce-stabilized-zirconiabased ceramics, Acta Mater., 2020, 183, 261-273

[28] Liu T., Characterization of Three-Dimensional Through-Thickness Transformation Zone in 9-mol\%-Ce-TZP Ceramics, J. Am. Ceram. Soc., 1994, vol.77, pp. 2203-206.

[29] Chevalier J., Gremillard L., Virkar A. V., Clark D. R., The Tetragonal-Monoclinic Transformation in Zirconia: Lessons Learned and Future Trends, J. Am. Ceram. Soc., 2009, vol. 92, no. 9, pp. 1901-1920.

[30] Aveston, J., Cooper, G. A. and Kelly, A., Conference on the Properties of Fibre Composites, Natl. Phys. Lab., Teddington, UK, 1971.

[31] Swain, M. V., Hagan J. T., Some observations of overlapping interacting cracks, Eng. Fract. Mech., 1978, vol.10, no.2, pp. 299-304.

[32] Rose L. R. F., Swain M. V., Transformation zone shape in ceria partially-stabilized zirconia, Acta Metall., 1988, vol. 36, no. 4, pp. 955-962. 
Figure 1.

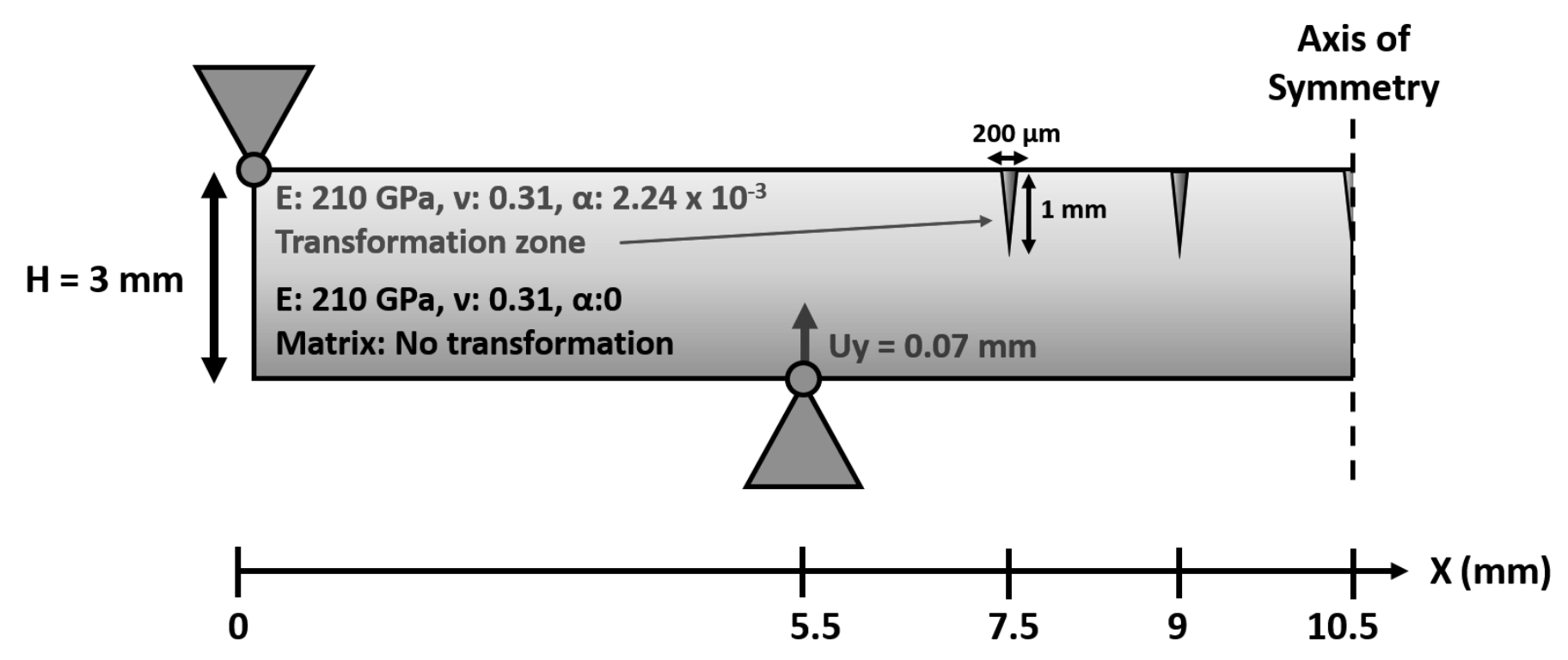

Axis of

Symmetry 
Figure 2.

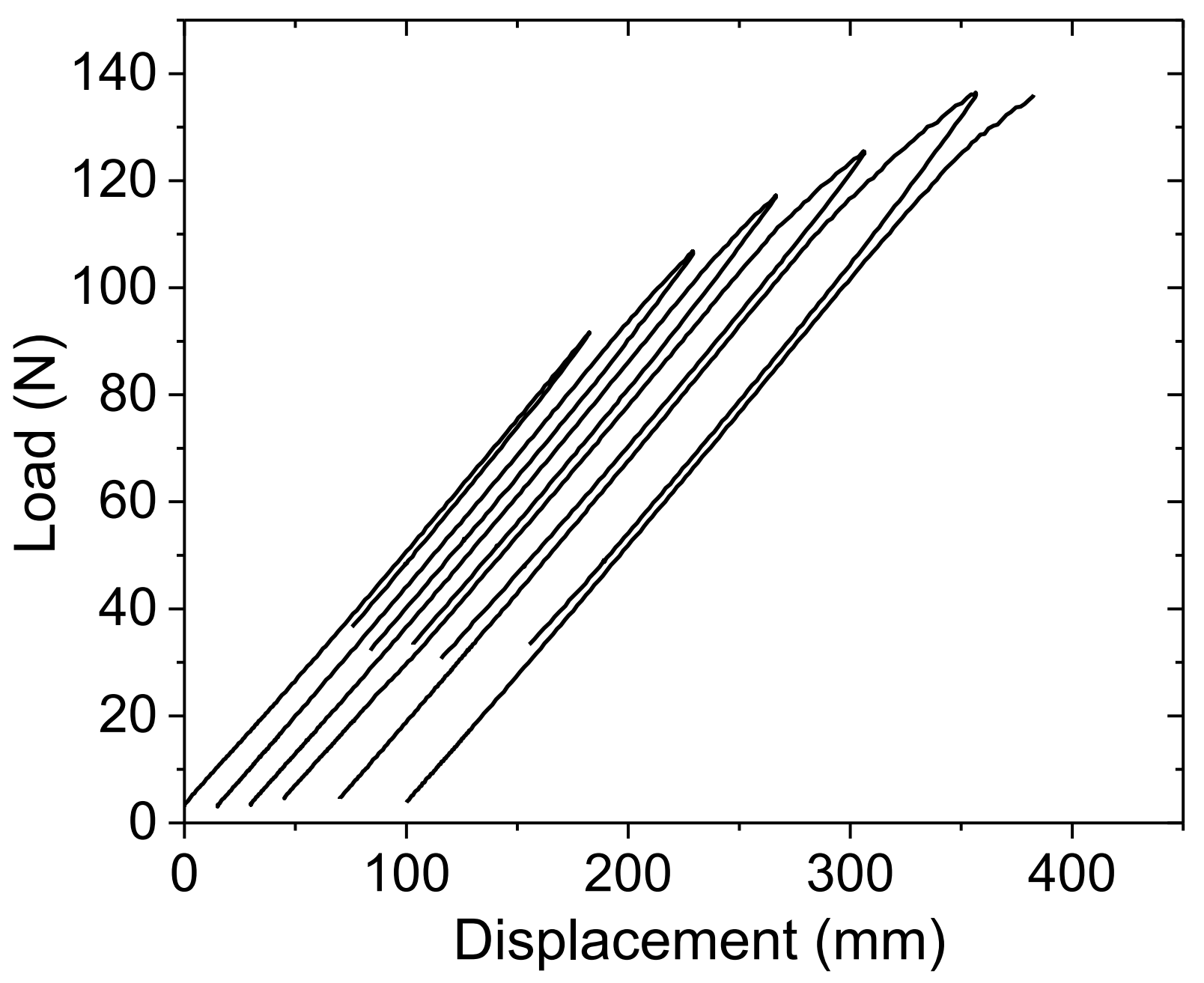


Figure 3.

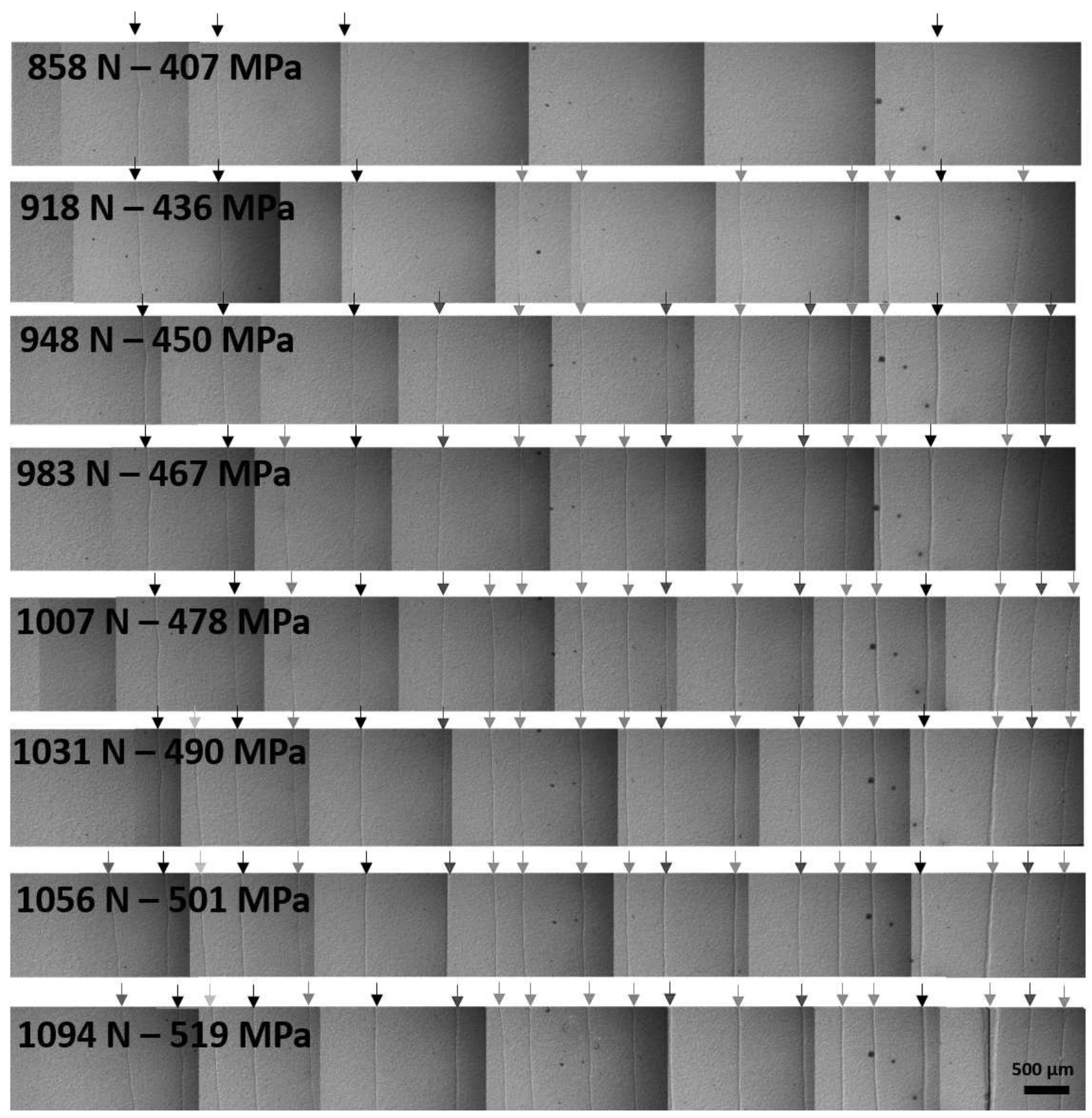


Figure 4.
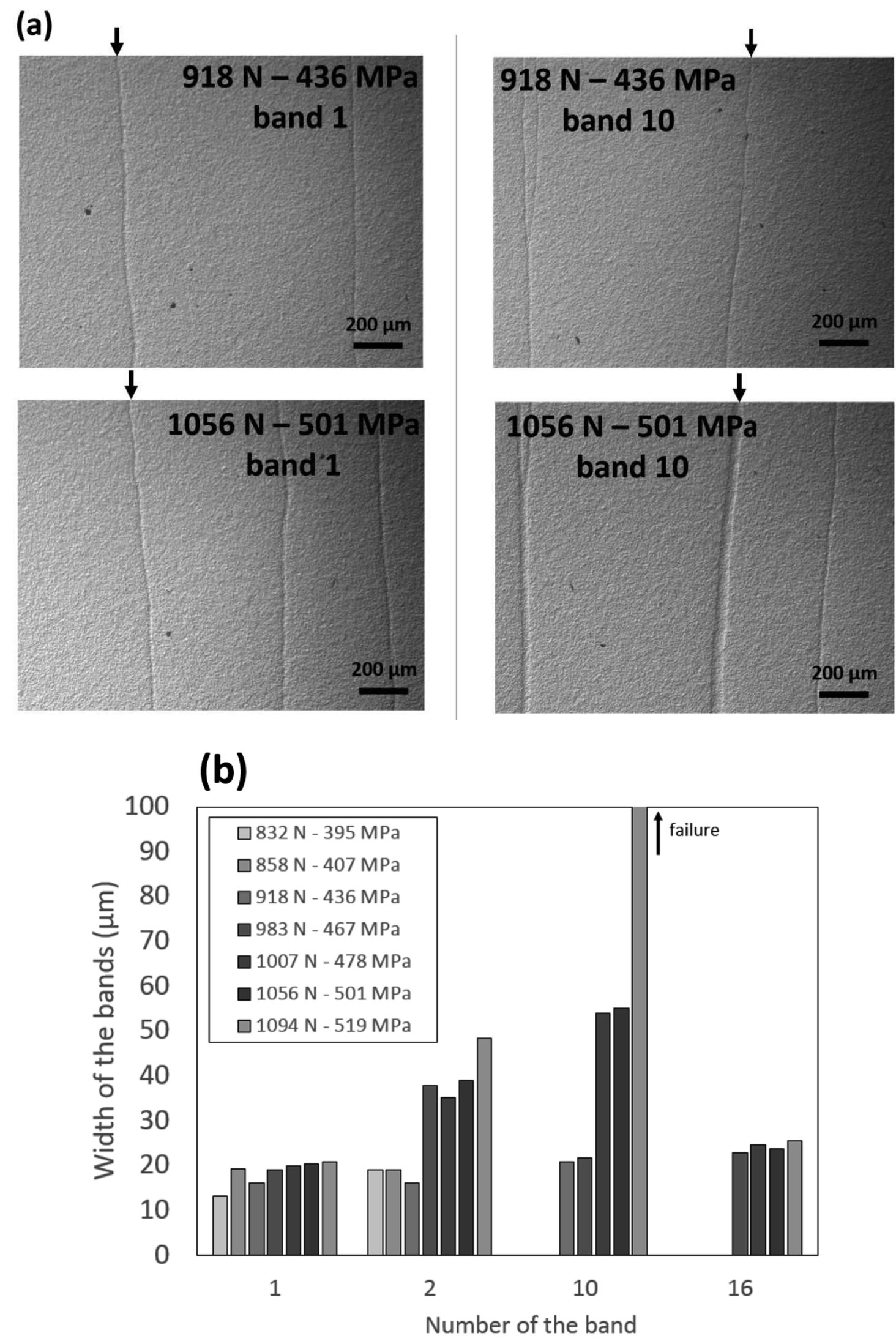
Figure 5.

(a)
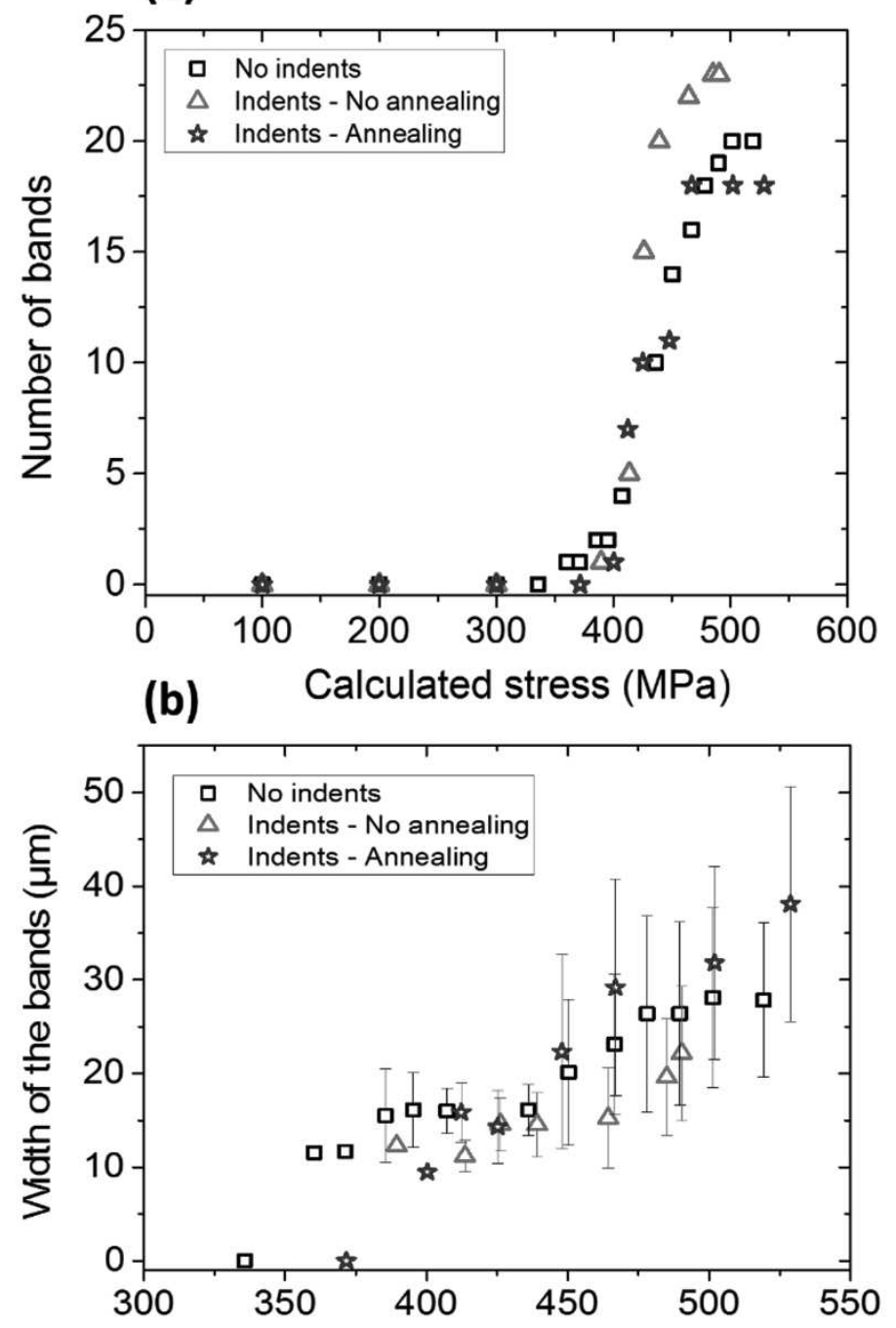

(c) Calculated stress (MPa)

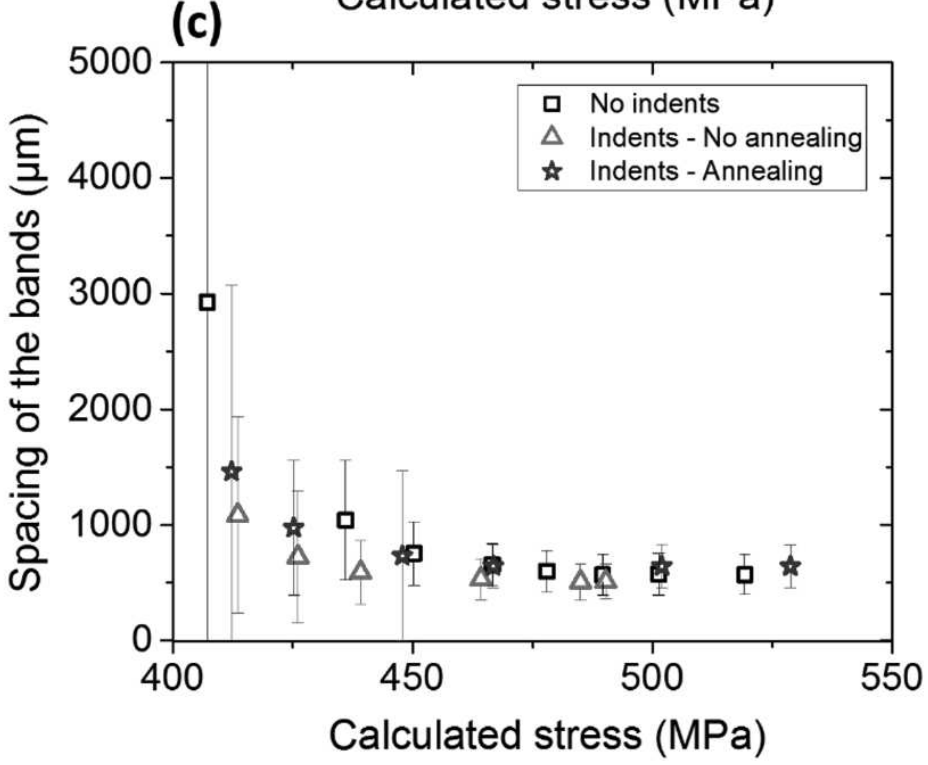


Figure 6.

(a) No annealing - $960 \mathrm{~N}-450 \mathrm{MPa}$

Indents
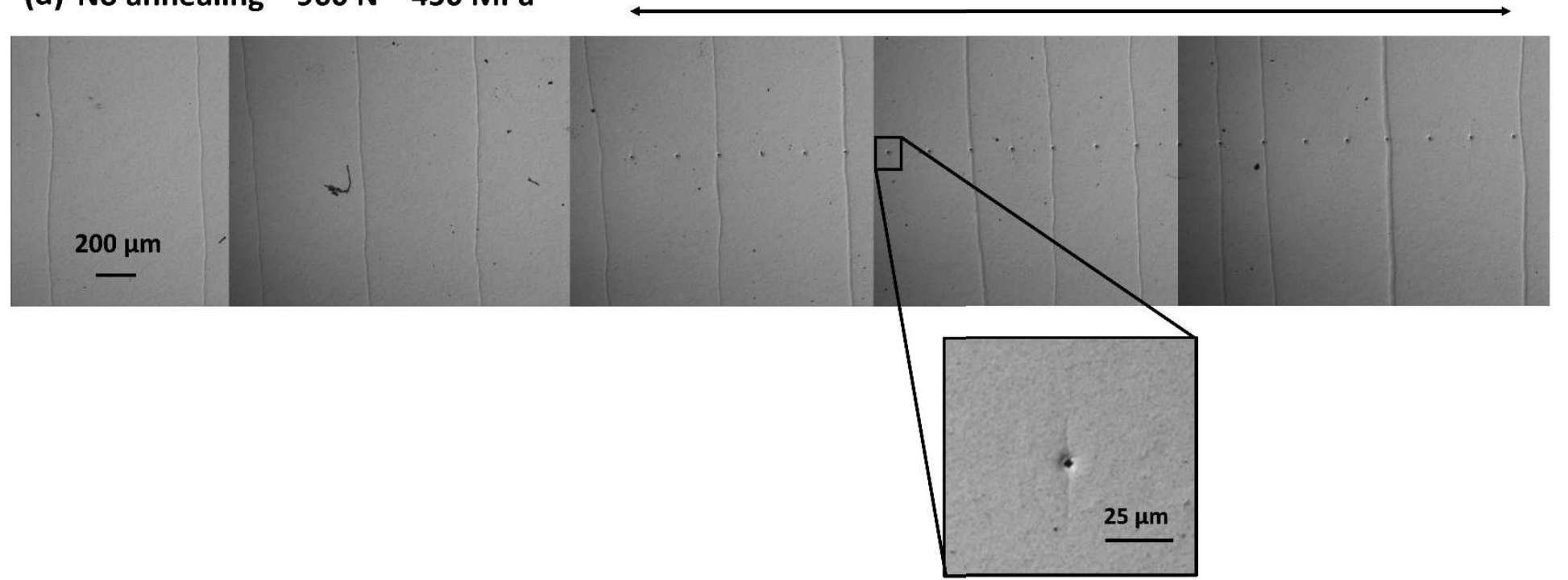

(b) Annealing - 960 N-450 MPa

\section{Indents}

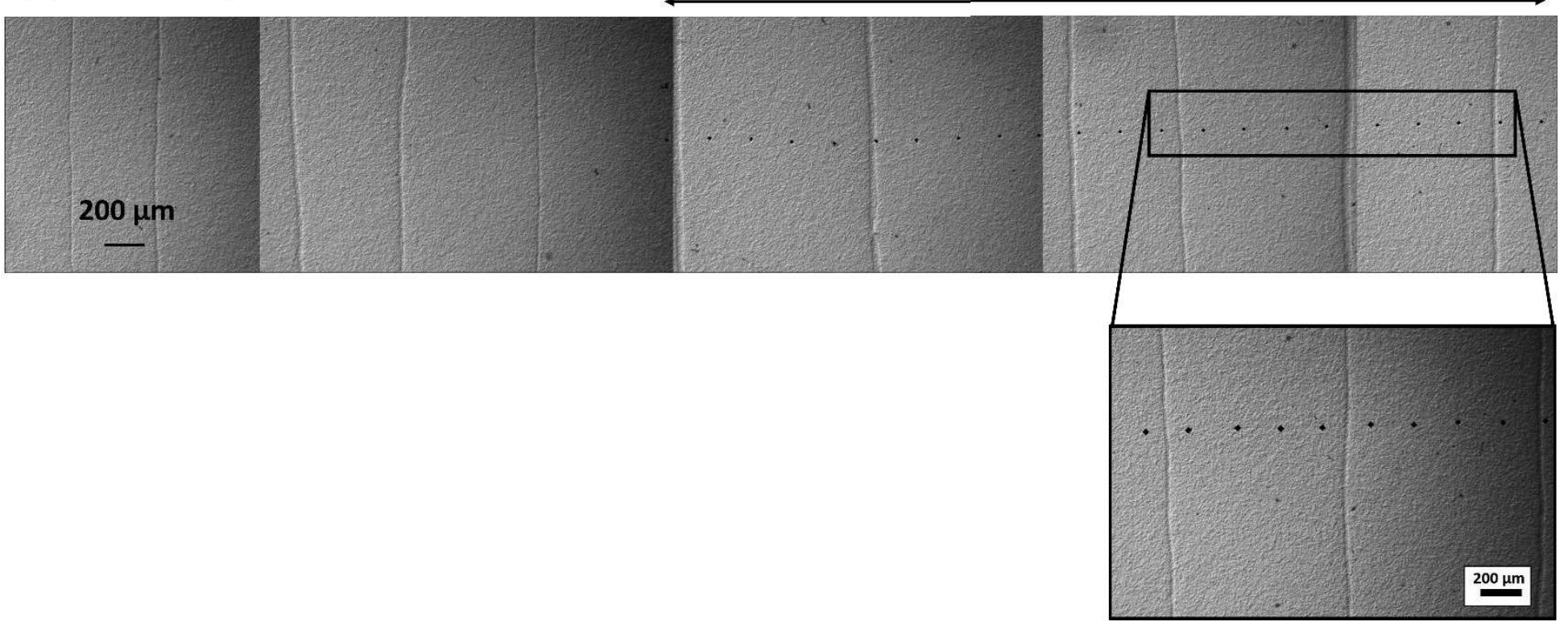


Figure 7.
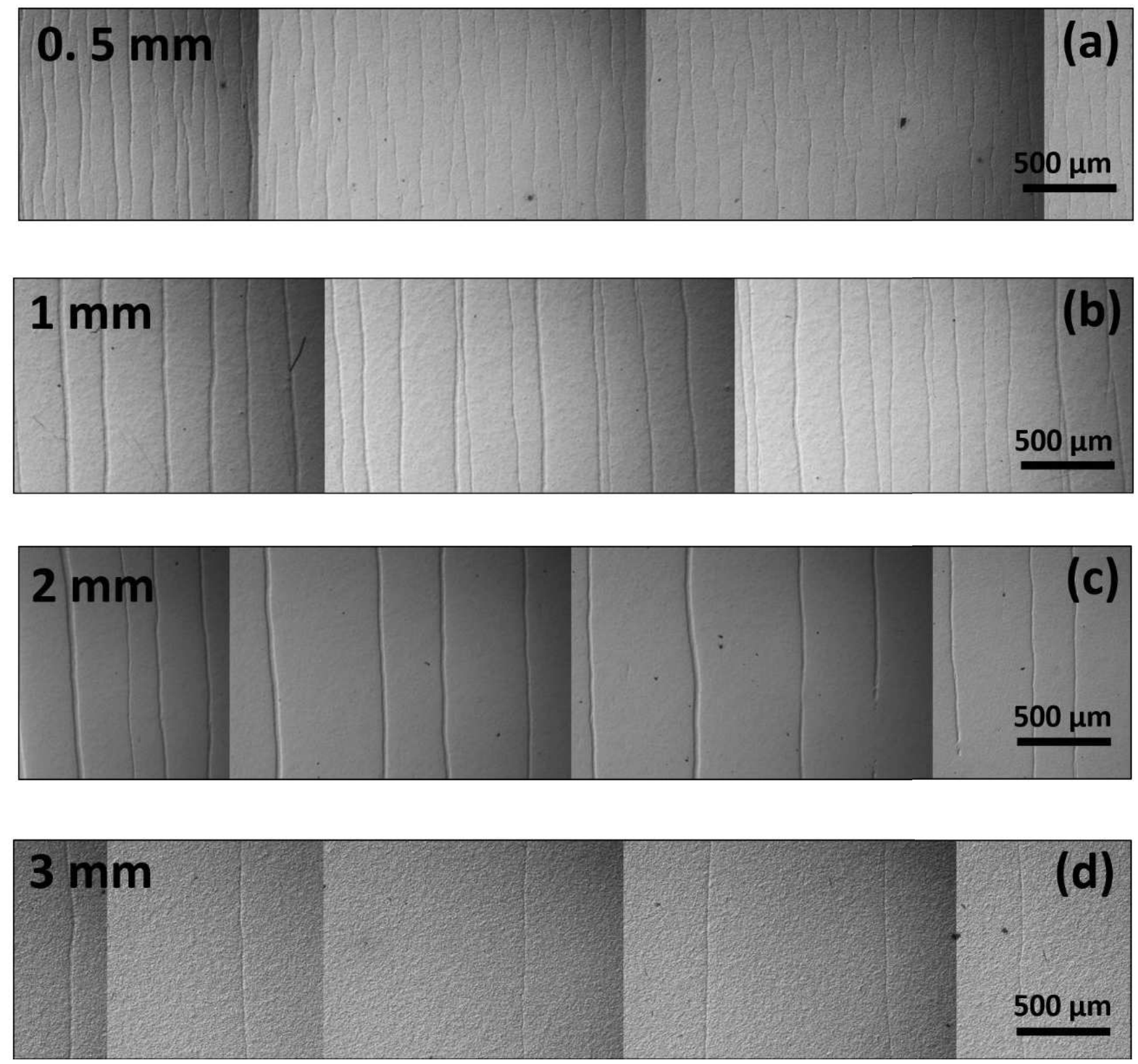
Figure 8.
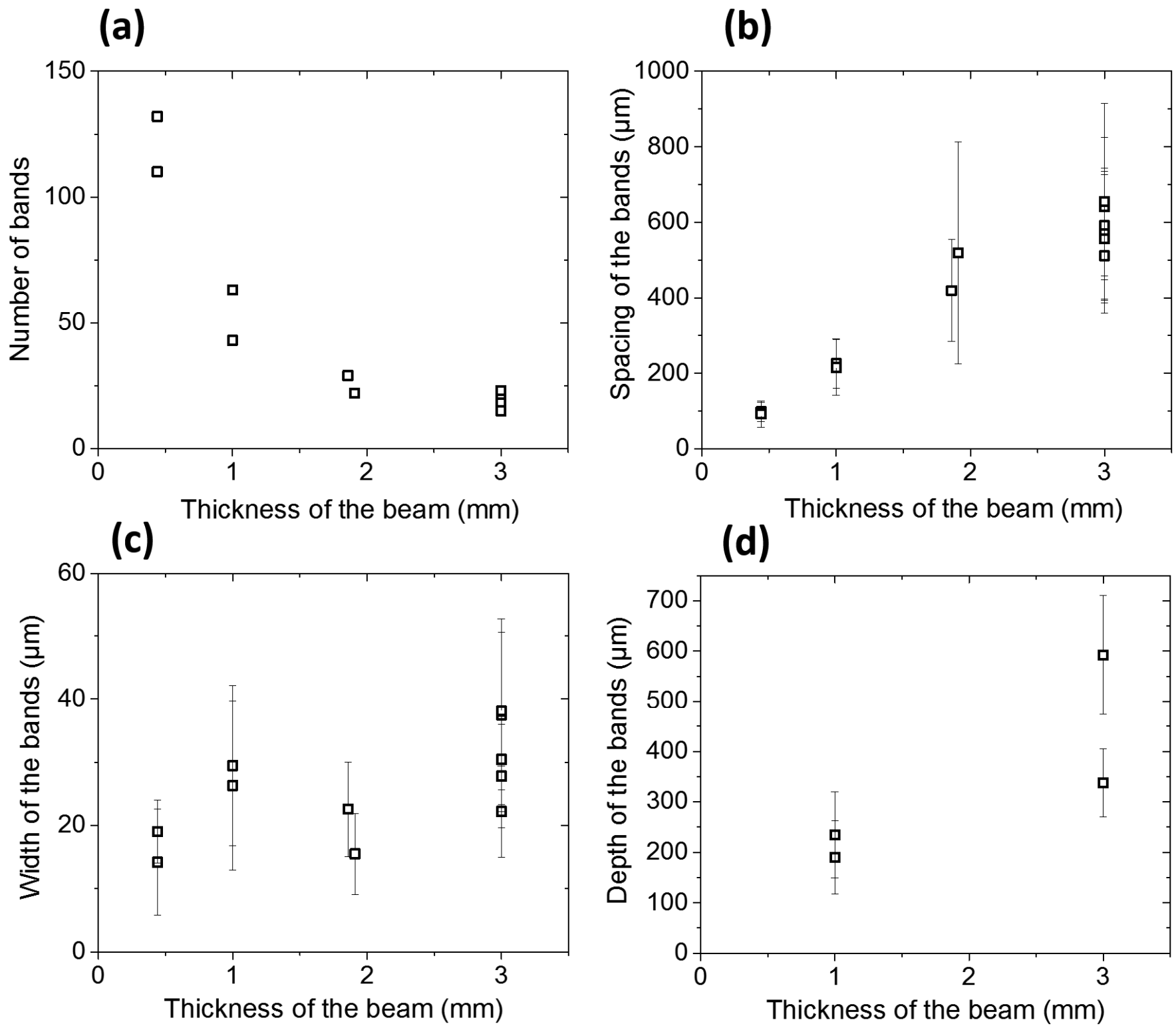
Figure 9.

(a)

Tensile side
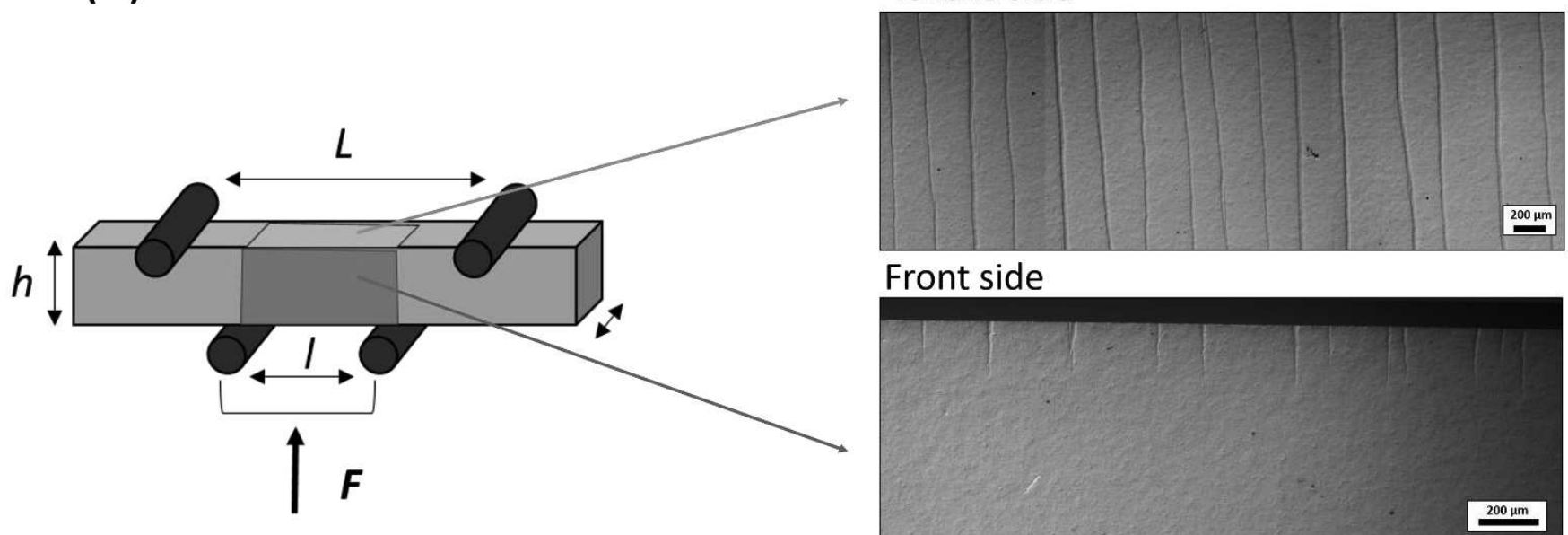

Front side

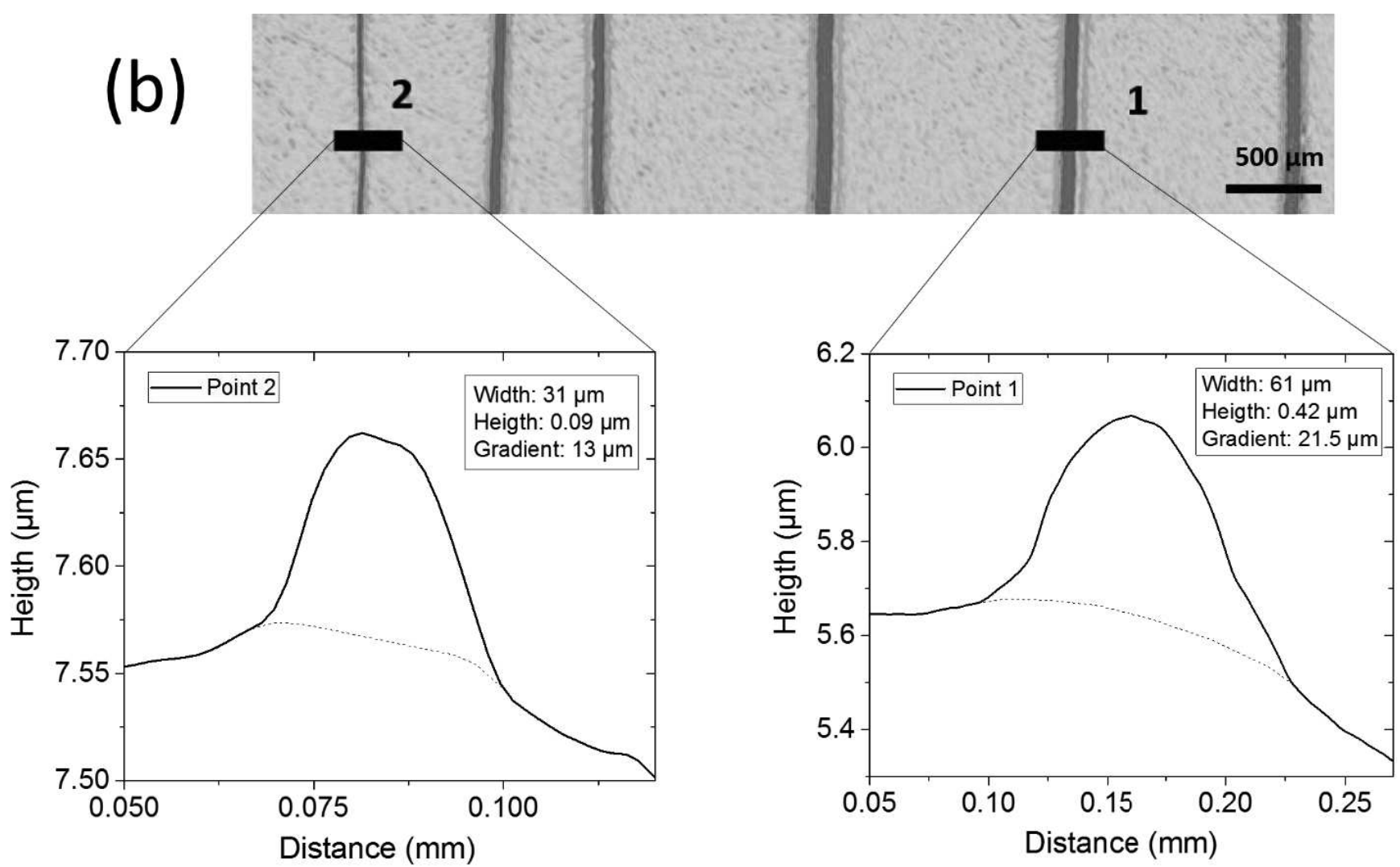


(c)

\section{Schematic illustration of a transformation band

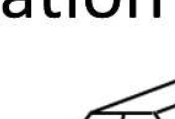

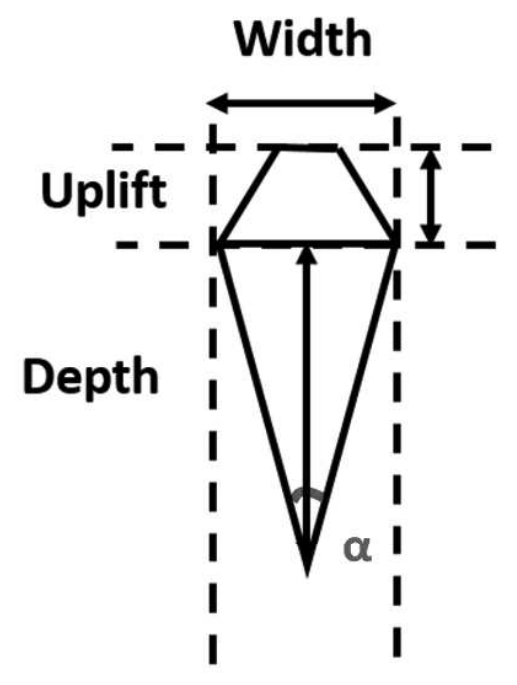

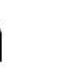

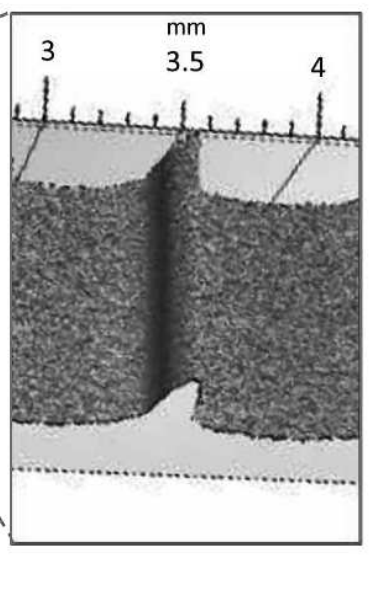


Figure 10.

(a)

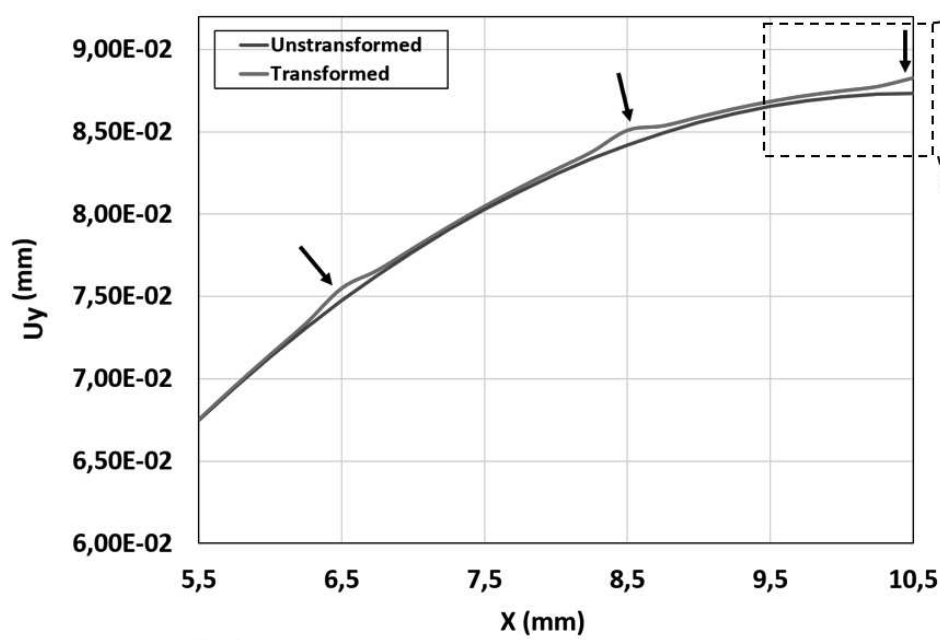

(c)

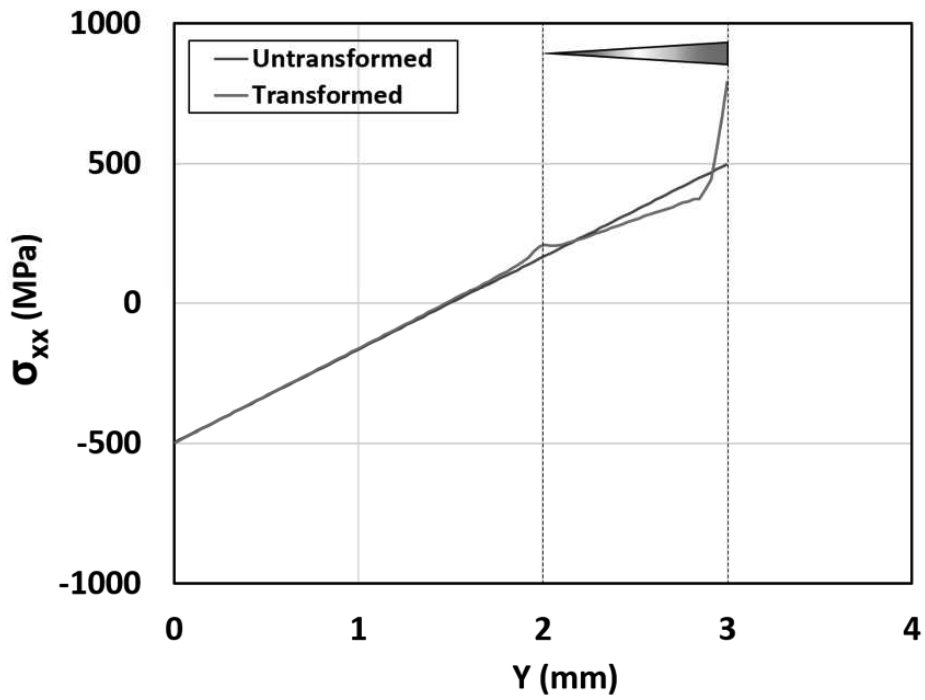

(b)

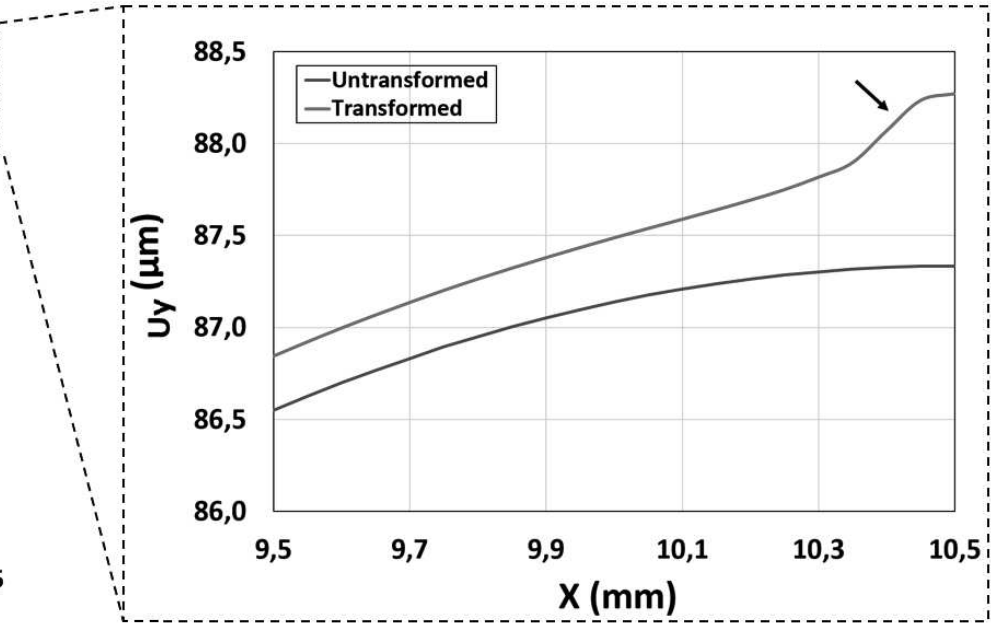

(d)

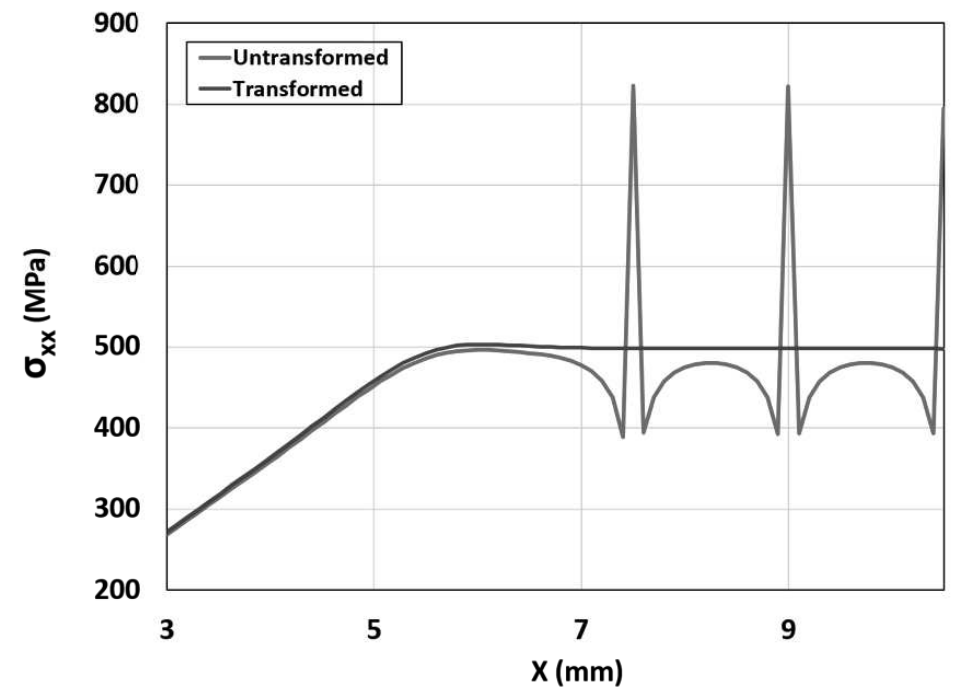


Figure 11.

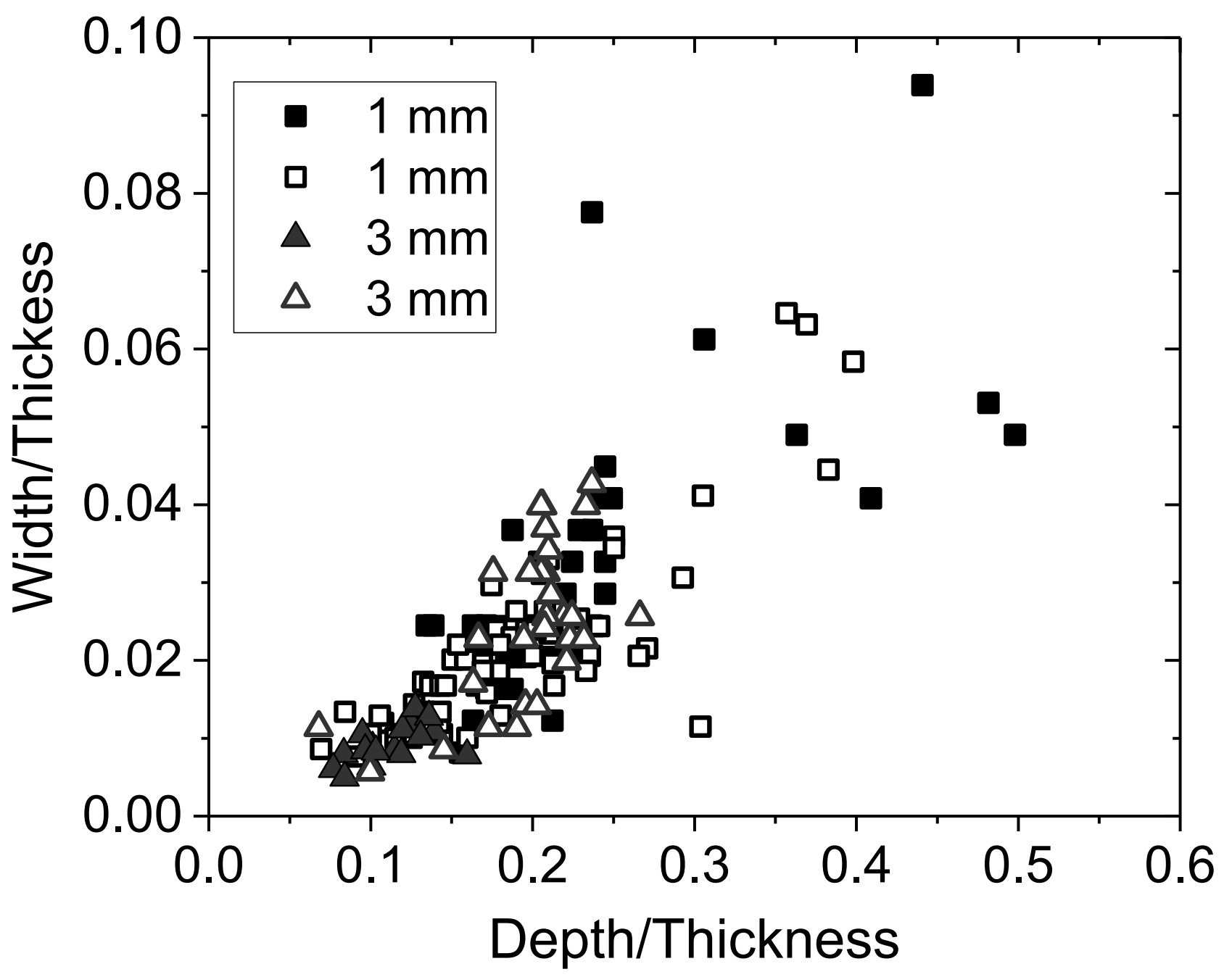




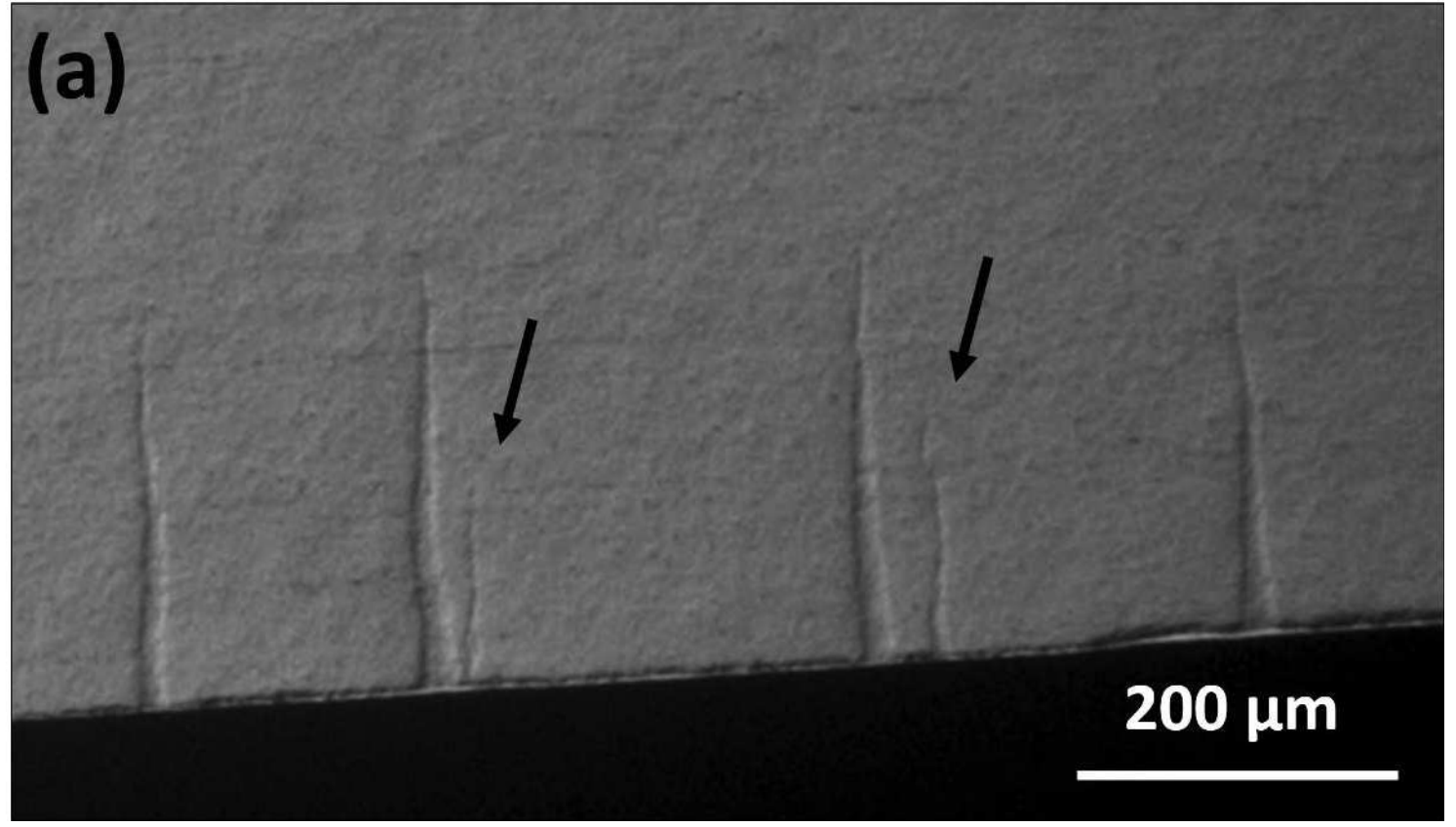

Outside the stress

shielding zone, a new

band can propagate

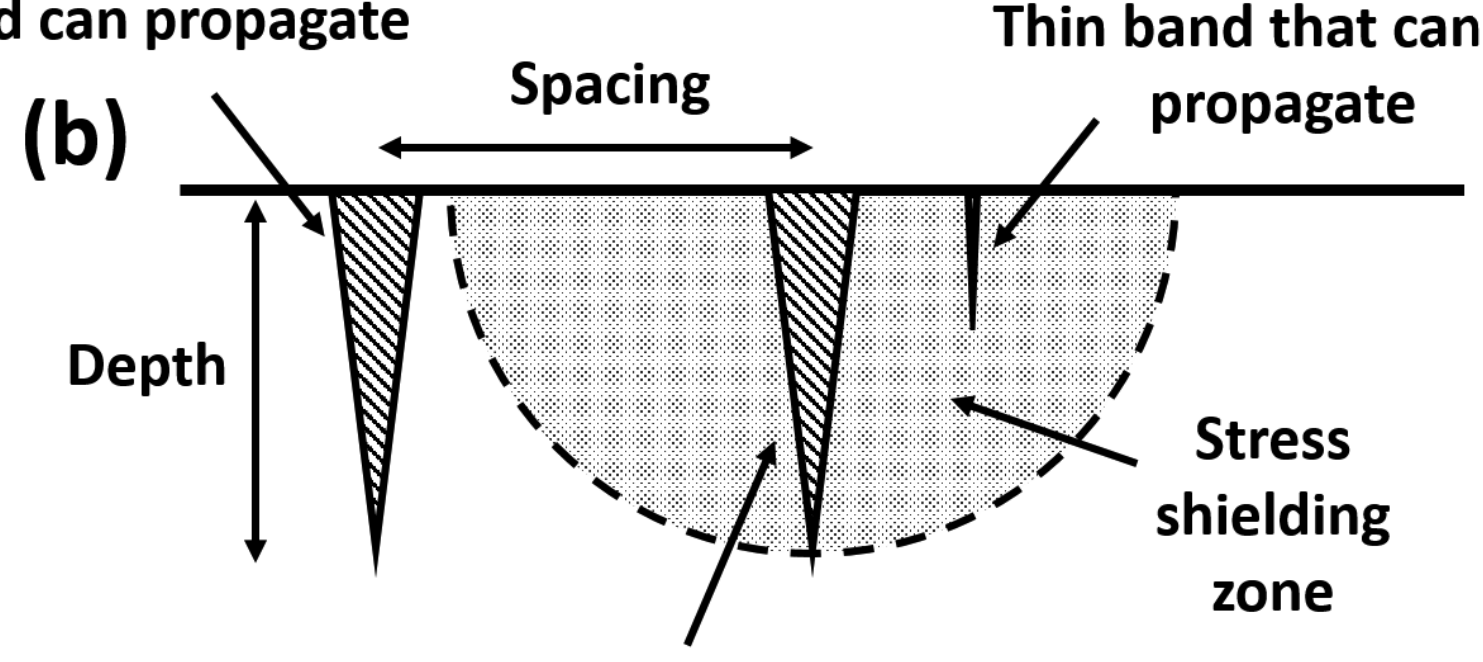

Large band shielding the thin band to propagate 


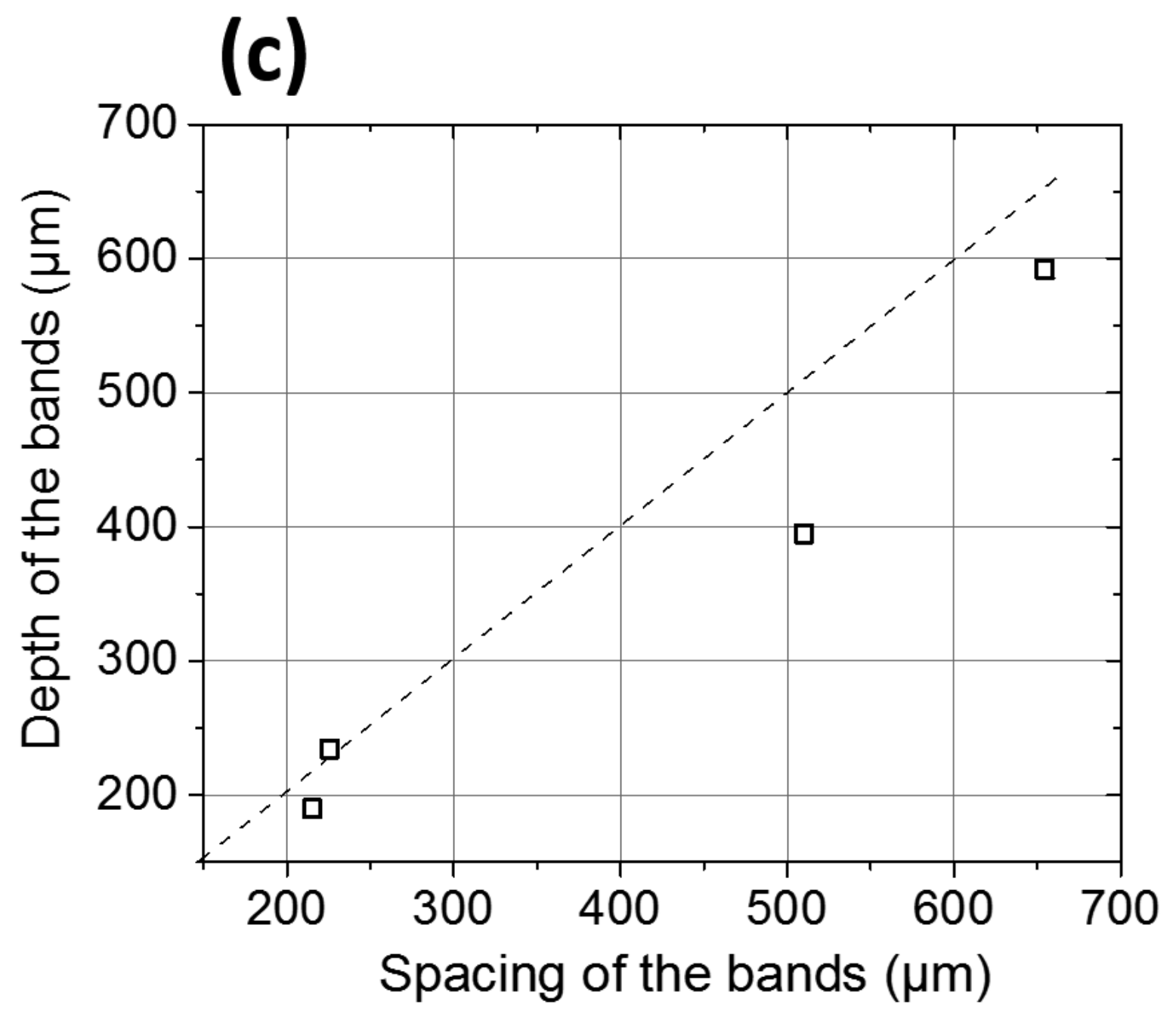


Figure 13.

(a) $3 \mathrm{~mm}$ thick $-1000 \mathrm{~N}$

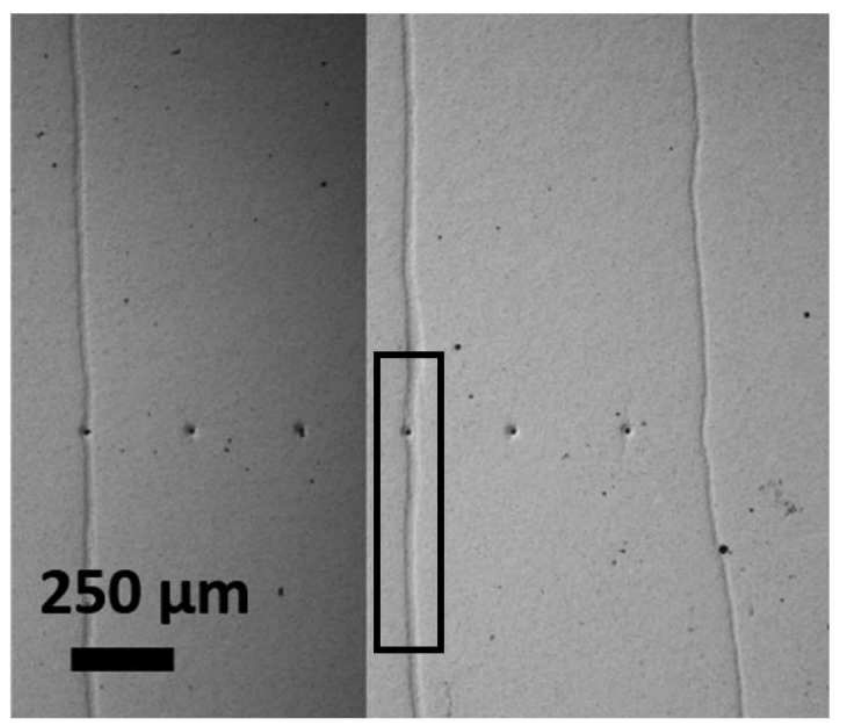

(b) $3 \mathrm{~mm}$ thick - $1016 \mathrm{~N}$ - break

\section{(c) $2 \mathrm{~mm}$ thick - At break}
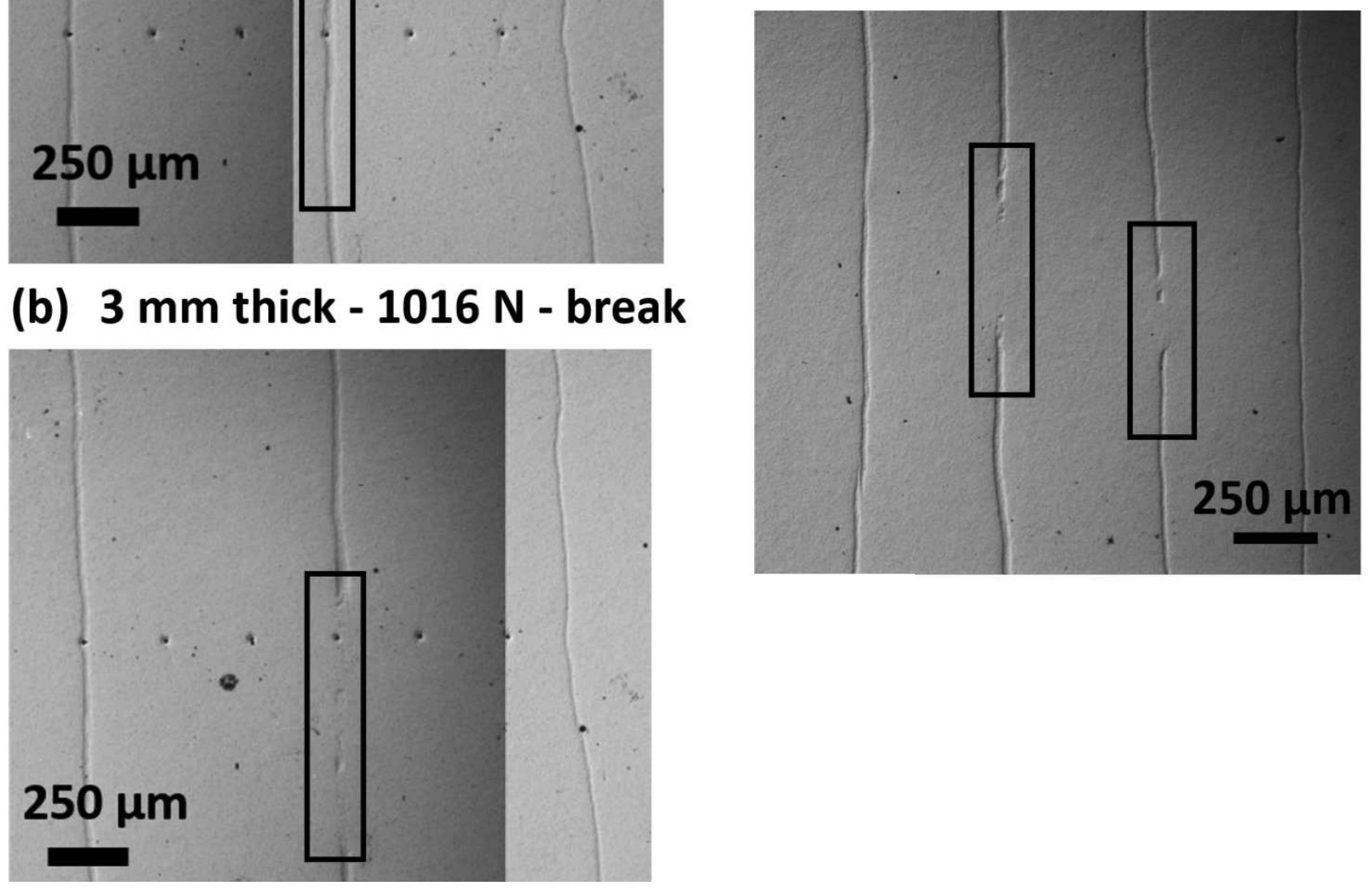


\section{FIGURES CAPTIONS}

Figure 1. Schematic illustration of the 2D FEA model applied to simulate the stress state inside and adjacent transformation bands during $4 \mathrm{~PB}$ test.

Figure 2. Typical example of a load/displacement curve obtained on a $1 \mathrm{~mm}$-thick sample during loading/unloading 4PB test at a cross-head speed of $0.1 \mathrm{~mm} / \mathrm{min}$. Significant amount of plasticity is observed, reflected by a non-linear behavior and a permanent strain after each unloading.

Figure 3. Optical images in Nomarski contrast of a 3mm-thick sample tested at a cross-head speed of $0.1 \mathrm{~mm} / \mathrm{min}$ for different loading values. Arrows indicate the transformation bands in their order of appearance (black, orange, red, blue, green, yellow and grey respectively).

Figure 4. (a) Optical images using Nomarski contrast of two different bands with their associated order of appearance (band 1 and band 10 are respectively the first band and the $10^{\text {th }}$ band that were formed at the tensile surface of the beam) at two different loads (918 $\mathrm{N}$ and $1056 \mathrm{~N}$ ). (b) Width of the bands as function of the bands' number referred here as their order of appearance, for four different bands (number 1, 2, 10 and 16 (i.e. first, second, $10^{\text {th }}$ and $16^{\text {th }}$ band to appear)) at different loads ranging from $832 \mathrm{~N}$ to $1094 \mathrm{~N}$. The images and values were taken from a $3 \mathrm{~mm}$ thick sample during incremental loading $(0.1 \mathrm{~mm} / \mathrm{min})$.

Figure 5. (a) Number, (b) width and (c) spacing of the transformation bands as function of the applied calculated stress for three different samples: one without indents (black squares), two with indents on half of the inner span length and positioned every $200 \mu \mathrm{m}$ (without annealing (red triangles) and with annealing after indentation (blue stars)). Tests were performed on $3 \mathrm{~mm}$ thick samples at a cross-head speed of $0.1 \mathrm{~mm} / \mathrm{min}$. Error bars, indicative of the standard deviations of the measurements are indicated on the graphs.

Figure 6. Optical images obtained with Nomarski interferences at a load of $960 \mathrm{~N}$ of $3 \mathrm{~mm}$ thick samples tested at $0.1 \mathrm{~mm} / \mathrm{min}$ with indents on half of the inner span length and positioned every $200 \mu \mathrm{m}$. (a) Sample without annealing (residual stresses present). (b) sample after annealing $\left(1200^{\circ} \mathrm{C}-30 \mathrm{~min}\right)$ (no more indentation residual stresses). Insert are shown 
for each sample, showing transformation bands starting from the indents' edges for the nonannealed sample (a) and bands located between indents for the annealed sample (b).

Figure 7. Optical images obtained in Normarski contrast showing 4 different samples (a) 0.5 $\mathrm{mm}$, (b) $1 \mathrm{~mm}$, (c) $2 \mathrm{~mm}$ and (d) $3 \mathrm{~mm}$ thick, at a calculated stress of $450 \mathrm{MPa}$ for each sample, exhibiting different transformation bands' features (number, width and spacing).

Figure 8. (a) Number, (b) width, (c) Spacing and (d) depth of the bands vs sample thickness (values at breakage).

Figure 9. (a) Schematic illustration of a 4PB sample with optical images obtained by Nomarski contrast on a $1 \mathrm{~mm}$ thick sample. (b) Image in false color obtained after optical interferometry and image analysis (image $\mathrm{J}$ software) of a 3mm-thick sample after 4PB test with related profiles on both a thick band (profile 1) and a thin band (profile 2). (c) Schematic illustration of a transformation band with the related interferometry images showing the uplift and the height of one transformation band.

Figure 10. Results obtained by Finite Element Modeling (FEM) (a) Displacement $U_{y}$ along the sample's length $(x)$ (the insert is showing a higher magnification of Uy variations for $\mathrm{x}=$ $9.5-10.5 \mathrm{~mm}$ ). Uplifts are indicated by arrows. (b) Nominal $\sigma_{x x}$ stress along the samples' thickness $(y)$ and (c) nominal $\sigma_{x x}$ stress along the samples' length $(x)$. Blue curves are associated to the elastic behavior of the beam on all zones; red curves represent the case when the bands have also transformed (volume increase).

Figure 11. Variation of the width of the bands vs their depth for $1 \mathrm{~mm}$ thick and $3 \mathrm{~mm}$ thick samples, normalized by the thickness of the beam. Blue symbols represent two samples of $3 \mathrm{~mm}$ thickness; black symbols represent two samples of $1 \mathrm{~mm}$ thickness.

Figure 12. (a) Optical microscopy image in Nomarski contrast showing the side view of a sample after 4PB test with visible thin bands close to wider bands. (b) Schematic illustration of the stress shielding model developed in this study. (c) Depth of the bands as function of their spacing for $1 \mathrm{~mm}$ and $3 \mathrm{~mm}$ thick samples showing a linear and proportional relationship. 
Figure 13. Optical images in Normarki contrast of different samples showing visible reverse transformation after breakage and unloading: $3 \mathrm{~mm}$-thick sample with indents at (a) $1000 \mathrm{~N}$ (before failure) and (b) after breakage (1016 N). (c) Optical images of a 2mm-thick sample after breakage. Reverse transformation is visible on both samples after breakage only (black rectangles). 